\title{
Auditoria de desempenho governamental e o papel de Entidades Fiscalizadoras Superiores (EFS)
}

\section{Argumento}

O propósito fundamental deste ensaio é oferecer uma argumentação (Dunn, 1994; Hood e Jackson, 1991; Walton, 1992; Majone, 1989; Barzelay, 2001) sobre recentes políticas de gerenciamento público ${ }^{1}$ de auditoria e avaliação ${ }^{2}$ conduzidas por Entidades Fiscalizadoras Superiores (EFS). ${ }^{3}$ Tais políticas vêm refletindo a seguinte doutrina — as organizações públicas de controle externo da burocracia estatal devem balancear e integrar duas espécies de accountability democrática: accountability de conformidade e accountability de desempenho (Light, 1993:14; Barzelay, 1997:384, Pollitt et al., 1999:15, Hood et al., 1999: 6). ${ }^{4} \mathrm{O}$ texto visa encorajar à reflexão e ao entendimento sobre modelos e estratégias que vêm sendo internacionalmente adotados por instituições centrais de controle da administração pública para a condução de recente modalidade de revisão governamental denominada auditoria de desempenho (performance auditing). ${ }^{5}$

\section{Delineando o estudo de uma nova disciplina}

O estudo do controle burocrático pode ser inicialmente abordado com a formulação de uma questão: desempenho ou conformidade? O que devem as EFS controlar? A resposta a essa questão diz respeito à adequada estratégia organizacional e ao melhor modelo de controle da burocracia estatal dessa espécie de instituição e comporta várias abordagens. O presente estudo trata de uma parte dessa questão que se relaciona ao controle 
do desempenho da gestão pública realizado por EFS, por meio de uma modalidade de avaliação e revisão específica denominada auditoria de desempenho. Esse refinamento do estudo de maneira alguma torna a questão inicial menos complexa. Desempenho e conformidade são partes que se vêm demonstrando atuações complementares do controle burocrático. Não há registro de EFS que tenha abandonado a visão mais tradicional de guardiã da gestão pública por meio de verificações da conformidade e legalidade dos atos de quem lida com o dinheiro, bem ou valor público. Contudo, a mais recente modalidade de revisão e controle da gestão estatal, com enfoque nos resultados, vem crescentemente consumindo os recursos e esforços de diversas EFS que buscam, além de garantir conformidade da gestão, avaliar, revisar e pesquisar o desempenho de atividades, projetos, programas, políticas e órgãos governamentais.

Para fins de análise da auditoria de desempenho como uma disciplina autônoma, esta deve ser situada em um campo de estudo pertencente a políticas de gerenciamento do setor público. Tais políticas visam aperfeiçoar áreas de ação governamental, tais como: finanças públicas, orçamento público, serviço público e relações trabalhistas, planejamento de despesas e receitas públicas, compras no setor público, auditoria e avaliação da atividade governamental. Estas duas últimas áreas são as de interesse para o presente ensaio. Ao abordar o processo de formulação e implementação de políticas de gerenciamento público relacionado com a auditoria e avaliação, três dimensões da auditoria de desempenho são analisadas, a saber: a dimensão política, a dimensão organizacional e a dimensão gerencial.

A análise da dimensão política da auditoria de desempenho permite concluir que apesar de pressões externas para adoção de práticas de auditoria mais qualitativas, no âmbito das instituições de controle, a estratégia e a adoção de determinados modelos de auditoria de desempenho por essas instituições são decorrentes de fatores políticos dentro dos Estados nacionais que dão forma e limitam (ou expandem) as possibilidades de atuação de uma EFS em uma auditoria de desempenho.

A dimensão organizacional permite a discussão e a análise de mudanças que vêm ocorrendo no âmbito das EFS com vistas a adequar sua estratégia organizacional para conduzir trabalhos dessa natureza. A dimensão organizacional revela ainda que o posicionamento, o grau de independência, as habilidades específicas do corpo de auditores e o tipo de relacionamento de uma EFS com os seus principais "clientes" (receptores de suas informações) são fatores também determinantes das escolhas estratégicas das EFS sobre a forma de condução de trabalhos de auditoria de desempenho.

O estudo da dimensão gerencial da auditoria de desempenho permite entender as transformações de práticas gerenciais voltadas para resultados e melhoria de desempenho tanto no âmbito da administração pública quanto 
das próprias EFS. Especificidades do gerenciamento público devem ser abordadas como forma de se discutir as limitações e possibilidades da auditoria de desempenho ser utilizada como ferramenta de aumento da accountability ${ }^{6}$ democrática e de melhoria do serviço público.

Os modelos e as estratégias de auditoria de desempenho são basicamente de duas naturezas: uma teórica e a outra empírica. Entende-se como de natureza teórica os modelos e as estratégias que se baseiam em fontes eminentemente conceituais. Tais fontes incluem análise de políticas públicas, teorias de gerenciamento, teoria do controle, administração pública, auditoria, ciência política, entre outras. Os de natureza empírica buscam evidências em práticas desenvolvidas pelas EFS relativas à atividade de auditoria e avaliação na esfera governamental para criar seus modelos, inclusive comparados.

\section{O posicionamento estratégico das EFS}

Uma constatação inicial ao estudar o fenômeno da auditoria de desempenho é que não existe ainda uma definição clara sobre o que seja controlar o desempenho da gestão pública. ${ }^{7}$ Por exemplo, o posicionamento estratégico de uma EFS com relação a essa modalidade de auditoria pode ser o de aceitar as políticas públicas formuladas como inquestionáveis quanto ao seu mérito ou conteúdo (a exemplo da EFS Britânica). ${ }^{8}$ Nessa perspectiva, o papel da EFS pode ser o de controlar a efetividade dos resultados de implementação das políticas públicas formuladas pelas instâncias governamentais competentes vis-à-vis os objetivos estipulados na própria política; ou pode a EFS, nesse contexto, controlar a eficiência da condução de determinado programa ou projeto relativamente aos produtos gerados e resultados alcançados vis-à-vis os custos para produzi-los; ou, ainda, pode a EFS analisar a observância de boas práticas de gestão dos agentes públicos responsáveis pela condução de determinada política pública. Nesses três casos, é bastante preciso dizer que o auditor está conduzindo trabalhos de auditoria de desempenho. Contudo, não é correto dizer que o desempenho da política analisada é independente de conformidade, ou somente orientado para resultados. A auditoria de desempenho tem um enfoque mais preciso nos resultados. Cuida com menos rigor dos aspectos de conformidade da gestão. Mas, de forma alguma pode ser caracterizada como uma atividade típica, homogênea, linear, ou, se preferirem, com um arcabouço metodológico perfeitamente definido, inclusive quanto ao objeto de controle, os critérios de investigação e os métodos utilizados nos trabalhos, conforme aprofundaremos adiante no presente estudo. 
Em um outro cenário e considerando ainda a dificuldade de definição do nosso objeto de estudo - a auditoria de desempenho — pode-se tomar como exemplo uma EFS que adote uma estratégia organizacional na qual a dicotomia política/administração ${ }^{9}$ se mostra mais irrelevante (a EFS norteamericana, por exemplo) e, assim, se posiciona de modo a questionar o mérito ou conteúdo de políticas públicas. Estaria uma EFS realizando auditoria de desempenho ao indicar caminhos alternativos de solução para políticas públicas que visem sanar determinados problemas sociais, econômicos ou distributivos? A resposta é que o ferramental metodológico que vem sendo utilizado em trabalhos de auditoria de desempenho permite tal análise e, ainda, é fato empírico que algumas EFS se propõem a esse tipo de verificação. ${ }^{10}$ Nessa perspectiva, a EFS posiciona-se em relação à política pública de forma menos atenta à dicotomia política/administração e interfere inclusive quanto ao mérito e conteúdo da política, e, nesse caso, analisa questões de eqüidade de política, distributividade, universalidade, custo/oportunidade da política, indica alternativas de atuação estatal, e assim por diante. Tais exemplos demonstram que a questão que envolve a auditoria de desempenho é multifacetada. Uma dessas faces da questão se refere à própria dificuldade em se definir o posicionamento estratégico adotado por uma EFS quanto ao que se deseja controlar no governo, bem como uma vez definido, como fazê-lo.

\section{A natureza da atividade de auditoria de desempenho: legitimando a atuação das EFS}

Uma segunda questão que deve ser enfrentada no estudo desta matéria relaciona-se com a própria dificuldade em se determinar o que seja a atividade de auditoria de desempenho, tanto do ponto de vista teórico quanto empírico.

Do ponto de vista teórico, há inclusive autores que afirmam que a auditoria de desempenho não é, na verdade, uma atividade de auditoria de fato, mas uma espécie de avaliação (Barzelay, 1997). Nessa perspectiva, e extrapolando essa afirmação, pode-se inferir que o auditor governamental ao conduzir trabalhos de auditoria de desempenho está exercendo uma atividade que vai além do seu papel tradicional de verificar a conformidade dos atos de gestão e, desta forma, estaria o auditor "invadindo" áreas de outros campos profissionais dentro da própria estrutura estatal.

O papel do auditor de desempenho percorre áreas de análise econômica, de consultoria administrativa, de pesquisas sociais e de análise de políticas públicas. Poder-se-ia argumentar que a análise econômica deveria estar sendo empreendida por unidades ou institutos de economia 
especializados; avaliações sobre o sucesso ou insucesso da gestão de um programa por consultorias administrativas; pesquisas sociais sobre o impacto da atuação do Estado por sociólogos e, finalmente, estudos sobre a efetividade dos programas sendo conduzidos por unidades de avaliação genérica composta por cientistas sociais altamente treinados. Advogados e contadores (a espinha dorsal da maior parte das EFS) teriam pouca participação nisso tudo. Esses especialistas deveriam estar trabalhando em formas tradicionais de auditoria de conformidade e, ainda, aperfeiçoando-se em recentes elementos de análise financeira, auditorias de riscos, trabalhos atuariais, e outros dessa natureza (Pollitt et al., 1999: 213).

O contra-argumento da retórica de que não existe legitimidade, no âmbito de instituições centrais de controle, para o desenvolvimento de trabalhos de auditoria de desempenho, é que essas instituições estão sendo cada vez mais demandadas para realizarem trabalhos mais qualitativos do ponto de vista de análise da eficiência, efetividade e economicidade (3 E's) da ação governamental. O profissionalismo, a independência institucional, a capacidade técnica e a posição que ocupa essa espécie de órgão nas administrações públicas nacionais permitem-lhe realizar trabalhos de maior credibilidade e com maior grau de independência sobre os aspectos dos 3 E's. Tais enfoques do controle vêm ganhando relevo para a consolidação de Estados democráticos (Aucoin, 1995: 6); para desfazer a imagem pública de ineficiência e não efetividade das ações implementadas por governos (CLAD, 1998); bem como para conter a crise fiscal por que passam os governos desde meados de 1980 (Majone, 1989). Esse talvez seja o argumento administrativo (Hood e Jackson, 1991) fulcral das reformas administrativas que vêm sendo implementadas por diversos países sob a rubrica de doutrinas da nova gestão pública.

Nessa veia, as EFS vêm se destacando como órgãos fundamentais para garantir a chamada accountability democrática, uma vez que os agentes políticos teriam informações relevantes sobre a implementação de políticas públicas por eles formuladas; accountability de resultados, à medida que os diversos interessados em informações sobre resultados de políticas teriam acesso a recomendações menos internas ao governo sobre seus programas e conseqüentemente teoricamente mais isentas; e finalmente accountability de melhoria da administração pública, pois o próprio governo pode se beneficiar das recomendações contidas em trabalhos de auditoria de desempenho com vistas a promover melhorias na sua atuação. Cabe notar que essa dimensão da atuação das EFS com enfoque em resultados é complementar as outras modalidades de controle e revisão que se preocupam em garantir outra forma de accountability, a de conformidade ou legalidade, também estritamente relevante para consolidação de um Estado democrático e livre de impropriedades administrativas, por meio de gerentes públicos no exercício de suas funções administrativas. 
De modalidade recente, muitas vezes observada como decorrente dos processos de transformação por que passam diversas administrações públicas, conhecidos como reformas administrativas, a atividade de auditoria de desempenho é, sem dúvida, um dos mais notáveis desenvolvimentos dentro de modernas administrações públicas que se preocupam com o resultado de suas ações. A auditoria é definida, neste contexto, como um conjunto de métodos e procedimentos para obtenção de informações relevantes de controle. ${ }^{11}$ Ela pode ser de desempenho ou conformidade/ legalidade/financeira. $\mathrm{O}$ presente estudo trata da auditoria de desempenho.

Ao estudar a auditoria de desempenho, pode-se obter uma visão mais sistêmica do funcionamento da máquina administrativa e de como ela se organiza para prestar serviços e criar valor público (Moore, 1995). $\mathrm{O}$ auditor de desempenho, muitas vezes, busca soluções bastante criativas para recomendar mudanças com vistas a se obter um resultado da atuação do Estado melhor, mais eficiente e mais efetivo. Esse é o desafio dessa nova disciplina, esse é o desafio por que passam diversas EFS, auditores de desempenho e estudiosos do assunto.

\section{Em busca de uma definição: natureza e objeto}

Não existe uma definição única que contemple o que significa auditoria de desempenho. Diversos autores e mesmo instituições de auditoria utilizam-se das definições por eles estipuladas de forma a adequá-las ao contexto que pretendem analisar ou nos quais desejam atuar. Em termos mais genéricos, auditoria de desempenho pode ser definida como uma modalidade de revisão e avaliação da atividade governamental com enfoque no resultado da gestão pública.

Do ponto de vista instrumental, a auditoria de desempenho também pode ser mais precisamente definida como um conjunto de procedimentos técnicos e métodos de investigação utilizados por instituições centrais de controle da administração pública para obtenção, processamento e disseminação de informações relevantes de revisão e avaliação de atividades, projetos, programas, políticas e órgãos governamentais quanto a aspectos de economia, eficiência e efetividade, boas práticas de gestão, eqüidade, alcance de metas, capacidade de gerenciamento de desempenho, informações de desempenho, entre outros critérios orientados para o resultado da atuação pública.

\section{Eficiência, economia e efetividade}

O critério é a base de todos os julgamentos. Os trabalhos de auditoria de desempenho envolvem a aplicação explícita ou implícita de alguns 
critérios por meio dos quais o auditor irá julgar o comportamento da atividade, da organização ou do projeto que está sendo avaliado ou controlado. Os fatos encontrados em determinado trabalho de auditoria devem ser confrontados com algum critério, com vistas a auxiliar o auditor a fazer algum julgamento ou recomendação.

Os critérios mais tradicionais e conhecidos que envolvem o conceito de auditoria de desempenho relacionam-se com os 3 E's da gestão pública. O modelo de insumo-produto é o mais apropriado para descrever os conceitos dos 3 E's.

De acordo com Gray, Jenkins, e Segsworth (1992), as principais medidas de mérito embutidas no conceito de auditoria de desempenho são a economia, a eficiência e a efetividade. Economia geralmente significa a eliminação dos desperdícios de insumos; eficiência refere-se à otimização dos processos de transformação de insumos em produtos; e efetividade significa influenciar positivamente o impacto por meio da geração de produtos. A imagem de uma organização governamental eficiente está associada, neste caso, àquela na qual a atenção da administração está voltada para a otimização de processos produtivos flexíveis, bem como para a adaptação dos desenhos dos programas em função dofeedback recebido e das mudanças nas prioridades e nos objetivos das políticas públicas.

\section{Critérios da comunidade acadêmica e profissional}

\section{Intosai}

De acordo com a International Organisation of Supreme Audit Institutions - Intosai (Organização Internacional das Entidades Fiscalizadoras Superiores), auditoria de desempenho contempla diversos conceitos, tais como:

1) auditoria de economia de atividades administrativas de acordo com boas práticas de gestão, reconhecidos os princípios administrativos e as políticas de gerenciamento estabelecidas;

2) auditoria de eficiência da utilização de recursos humanos, financeiros e outros, inclusive o exame de sistemas de informações gerenciais, indicadores de performance e sistemas de monitoramento e os procedimentos estabelecidos pelas entidades auditadas para a melhoria de deficiências administrativas identificadas; e

3) auditoria de efetividade do desempenho em relação ao alcance dos objetivos estabelecidos para a entidade auditada; e auditoria do impacto atual das atividades, comparado com o impacto esperado (Intosai, 1992: 19). ${ }^{12}$

A Intosai apresenta as seguintes definições para economia, eficiência e efetividade: 
Economia: é a ação que consiste em reduzir, ao mínimo, o custo dos recursos empregados em uma atividade sem perda da qualidade.

Eficiência: representa a relação entre produto, em termos de bens, serviços e outros resultados, e os recursos utilizados para produzi-los.

Efetividade: é o grau com que os objetivos são alcançados e a relação entre os resultados desejados e os resultados reais de determinada atividade.

\section{Modelo de Pollitt: Inglaterra, França, Finlândia, Holanda e Suécia}

De acordo com Pollitt et al. (1999), a auditoria de desempenho está relacionada com o atendimento de alguns critérios categorizados da seguinte forma:

- economia;

- eficiência;

- efetividade;

- boa prática de gestão: consiste em testes que verificam se um auditado possui um bom sistema de contabilização, procedimentos de determinação de metas, se existe uma boa relação com os clientes; sistematicamente considera a função recursos humanos como a mais alta prioridade da organização, entre outros. A idéia central desse critério é que em várias áreas existe um razoável entendimento sobre o que constitui boa prática de gestão, e então as atividades atuais do auditado podem ser comparadas com modelos ou padrões de bom gerenciamento (benchmarking);

- boa governança: enquanto as boas práticas de gestão lidam com fatores mais internos à organização, o critério de boa governança estabelece uma visão mais sistêmica e externa à organização. Esse critério relaciona-se com a visão de coordenação das ações governamentais, que devido a uma série de fatores dentro das administrações públicas nacionais levam a fragmentação e perda de sinergia (ver Bardach, 1998 sobre a capacidade de colaboração entre agências governamentais);

- qualidade de serviço: o sucesso desse critério pode ser alcançado se um serviço público atinge as expectativas razoáveis de seus usuários; e

- atendimento de metas: envolve o estabelecimento da extensão na qual o órgão auditado fracassou ou obteve sucesso no atendimento de suas próprias metas, declaradas publicamente ou estabelecidas por normativos.

$\mathrm{Na}$ aplicação desses critérios em cinco EFS estudadas pelos autores (Inglaterra, França, Holanda, Finlândia e Suécia), conclui-se que critérios relacionados com a boa prática de gestão constituem grande parte dos trabalhos de auditoria de desempenho desenvolvidos por essas EFS. 
Critérios de eficiência e efetividade têm sido freqüentemente investigados em relação a essas questões, apesar da Intosai ter definido que os 3 E's constituem o cerne da auditoria de desempenho.

\section{Modelo de Barzelay: países da OCDE}

No ano de 1996, a Organização para Colaboração de Desenvolvimento Econômico (OCDE) reuniu especialistas em controle governamental de vários países-membros com a finalidade de identificar em que medida reformas administrativas expandiram o escopo dos trabalhos de instituições nacionais de auditoria, tanto externas (auditorias-gerais e cortes de auditorias e contas) como internas (inspetorias-gerais), para incluir questões relativas ao desempenho de administrações públicas nacionais. O principal produto desse evento foi consubstanciado em publicação daquela organização denominada Performance Auditing and the Modernisation of Government.

O modelo de Michael Barzelay foi o texto básico no que se refere às conclusões desse evento. De acordo com o autor, auditoria de desempenho é um nome incompleto para definir todos os modelos cognitivos mentais que essa atividade de avaliação e controle governamental incorpora. Os critérios de auditoria de desempenho, segundo Barzelay, podem ser vistos como subcategorias do nome auditoria de desempenho. Essas subcategorias são denominadas de tipos. Os tipos correspondem, de certa forma, aos critérios de auditoria, na concepção definida neste estudo. $\mathrm{O}$ autor identifica os seguintes tipos de auditoria de desempenho no âmbito dos países da OCDE, de acordo com o simpósio organizado:

1) auditorias de eficiência: examinam as funções organizacionais, os processos, e os elementos de programa para avaliar se os insumos estão sendo transformados em produtos de forma otimizada, especialmente no que concerne aos custos;

2) auditorias de efetividade de programa: examinam o impacto provocado pelos programas sobre os resultados finais;

3) auditorias de capacidade de gerenciamento do desempenho: buscam avaliar se o auditado tem capacidade para gerenciar processos e programas de forma eficiente e eficaz;

4) auditorias de informações de desempenho: verificam a precisão de informações não-financeiras geradas pelas próprias entidades examinadas. O órgão revisor não avalia a economia, eficiência ou efetividade de uma organização ou programa, mas, sim, formula um parecer sobre a veracidade das informações de desempenho fornecidas às instâncias superiores;

5) revisões da melhor prática de gestão: identificam onde um dado tipo de função está sendo desempenhado de forma excepcional e procuram discernir as razões daquele sucesso relativo; 
6) avaliações de risco: indicam aos formuladores de políticas públicas e gerentes do alto escalão os graves problemas que podem advir caso um programa seja mantido na mesma linha da operação. Esse tipo de auditoria de desempenho se diferencia das auditorias de efetividade de programa uma vez que não necessita posicionar-se quanto à efetividade do programa. O papel desse tipo de auditoria é o de identificar formas pelas quais os programas existentes possam sofrer interrupção no futuro e alertar os políticos e os gerentes quanto a essa possibilidade; e

7) revisões gerais de gestão: avaliam as organizações em vez de programas. Quando essas revisões vão além das auditorias de desempenho da capacidade gerencial, elas geralmente buscam as causas significativas para problemas ou sucessos persistentes na esfera do desempenho dentro de uma gama de atividades de um programa.

\section{Interface da auditoria de desempenho com a auditoria financeira e de conformidade e com a avaliação de programas}

A auditoria de desempenho e a auditoria financeira ou de regularidade diferenciam-se na maneira como elas são gerenciadas no âmbito das EFS. O modelo tradicional de auditoria consiste em um ciclo anual repetitivo de "checagem de livros", enquanto a auditoria de desempenho é conduzida por meio de um projeto específico (Pollitt et al., 1999: 16). A auditoria de desempenho envolve mais atores em seu processo e alcança públicos mais abrangentes da administração pública e constituintes externos que as tradicionais formas de auditoria de conformidade. À guisa de exemplificação de tal abrangência, a arena de definição de políticas públicas pode ser citada quando se conduz trabalhos de auditoria de efetividade, ou, ainda, quando se realiza avaliação de programas públicos. O impacto de relatórios de auditoria na opinião pública e sua repercussão na mídia tendem a crescer em trabalhos que tratam de questões de efetividade e gerenciamento de importantes operações governamentais. Finalmente, destaca-se que o processo de auditoria de desempenho é geralmente mais longo comparado com o de auditoria de conformidade, porque envolve mais questões metodológicas e é influenciado por mais atores.

Os critérios e métodos ${ }^{13}$ utilizados por EFS na condução de trabalhos de auditoria de desempenho são um avanço metodológico, se comparados com os tradicionais métodos de auditoria de coletar, analisar e disseminar informações. A auditoria financeira é um sistema rico em regras formais e procedimentos técnicos (Power, 1997:39). Há autores que argumentam que essa espécie de auditoria deverá tornar-se cada vez mais um produto 
de conformidade procedimental de regulação, removendo progressivamente o espaço dos profissionais de realizarem julgamentos (Hatherley, 1995). Por outro lado, os processos de condução de auditoria de desempenho têm proporcionado à atividade de auditoria governamental aproximação com outros campos do conhecimento, tais como Ciência Política, Administração Pública Comparada, Gerenciamento Público e Análise de Políticas Públicas, entre outros. ${ }^{14}$

Vinculada a atividades de pesquisas ou a estudos, a avaliação de programas busca analisar os processos ou impactos desses programas. A primeira atividade - processos — visa verificar se o programa está sendo implementado conforme seus objetivos, diretrizes e prioridades e se seus produtos estão atingindo as metas previstas com a necessária eficiência. A segunda atividade — impactos — busca aferir se as transformações primárias e/ou secundárias, na realidade, são atribuíveis às ações do programa, estabelecendo as devidas relações de causalidade (Garcia, 2001: 8).

Outra distinção que pode ser feita entre a auditoria de desempenho e a avaliação de programas refere-se ao papel exercido pelo auditor de uma EFS e um avaliador. Os auditores públicos são parte de um sistema de controle autorizativo dentro do conjunto de órgãos públicos que constituem a base de um governo democrático, e seus trabalhos são baseados empoderes estatutários e em mandatos que mais ou menos definem os limites de seu território de atuação. Pelo contrário, os avaliadores normalmente vêm de uma série de diferentes organizações que possuem mais liberdade de escolha de seu trabalho e de sua abordagem — de acordo com as limitações de verbas. À medida que a auditoria de desempenho é conduzida pelos órgãos centrais de auditoria, é correto afirmar que existe um senso de ter o papel de controle e guardiã, de manter a responsabilização de agentes públicos pelo gasto de dinheiro público. Na verdade, as EFS podem ter o papel de oferecer ajuda técnica para que os órgãos públicos melhorem seu gerenciamento, mas, apesar de importante, essa é uma função secundária de sua existência que não substitui sua função primária de guardiã.

Outra característica da avaliação é que ela também se preocupa com o monitoramento do desempenho de políticas públicas como parte de uma rotina de gerenciamento da própria atividade, enquanto a auditoria de desempenho é externa e independente do gerenciamento. Um dos principais enfoques da auditoria de desempenho consiste em auditoria de boas práticas de gestão (Barzelay, 1997; Pollitt, 1999) e processos padronizados no órgão auditado ou em sistemas de monitoramento e informações sobre desempenho, mais que na própria substância do desempenho.

O Quadro 1 busca sintetizar as principais características da auditoria de desempenho, auditoria de conformidade e avaliação de programas, de acordo com diversas dimensões que se julgam relevantes para a compreensão da atividade de controle na esfera governamental. 
Quadro 1: Distinção entre auditoria de desempenho, auditoria de conformidade e avaliação de programas

\begin{tabular}{|c|c|c|c|}
\hline & $\begin{array}{l}\text { Auditoria de } \\
\text { desempenho }\end{array}$ & $\begin{array}{l}\text { Auditoria de } \\
\text { conformidade }\end{array}$ & $\begin{array}{c}\text { Avaliação de } \\
\text { programas }\end{array}$ \\
\hline Foco & $\begin{array}{l}\text { Processo, produto } \\
\text { e impacto }\end{array}$ & $\begin{array}{l}\text { Insumos e } \\
\text { processo }\end{array}$ & $\begin{array}{l}\text { Produto e } \\
\text { impacto }\end{array}$ \\
\hline Critérios & $\begin{array}{l}3 \text { E's e outros } \\
\text { vinculados ao } \\
\text { desempenho }\end{array}$ & $\begin{array}{l}\text { Legalidade, } \\
\text { conformidade e } \\
\text { economia }\end{array}$ & $\begin{array}{l}\text { Efetividade, } \\
\text { eqüidade e } \\
\text { eficiência }\end{array}$ \\
\hline Métodos & $\begin{array}{l}\text { Auditoria, } \\
\text { monitoramento, } \\
\text { avaliação e } \\
\text { pesquisa }\end{array}$ & $\begin{array}{l}\text { Auditoria, investi- } \\
\text { gação de denún- } \\
\text { cias, consultas } \\
\text { públicas e } \\
\text { audiências }\end{array}$ & $\begin{array}{l}\text { Pesquisa, } \\
\text { monitoramento e } \\
\text { avaliação }\end{array}$ \\
\hline Produtos & $\begin{array}{l}\text { Pontos de } \\
\text { melhoria } \\
\text { identificados e } \\
\text { informações de } \\
\text { resultados } \\
\text { (accountability } \\
\text { de resultados) }\end{array}$ & $\begin{array}{l}\text { Irregularidades, } \\
\text { desconformidades } \\
\text { detectadas e } \\
\text { informações de } \\
\text { legalidade } \\
\text { (accountability } \\
\text { de conformidade) }\end{array}$ & $\begin{array}{l}\text { Informações de } \\
\text { causa/efeito } \\
\text { (accountability } \\
\text { de impacto da } \\
\text { ação do governo) }\end{array}$ \\
\hline $\begin{array}{l}\text { Impactos } \\
\text { esperados }\end{array}$ & $\begin{array}{l}\text { O governo } \\
\text { funcionando } \\
\text { melhor e de forma } \\
\text { mais democrática }\end{array}$ & $\begin{array}{l}\text { O governo } \\
\text { funcionando nos } \\
\text { limites da lei e dos } \\
\text { regulamentos } \\
\text { administrativos }\end{array}$ & $\begin{array}{l}\text { O governo } \\
\text { servindo melhor } \\
\text { a população. } \\
\text { Mais eqüidade } \\
\text { e mais justiça } \\
\text { social }\end{array}$ \\
\hline Área de atuação & $\begin{array}{l}\text { Programas, } \\
\text { órgãos, projetos e } \\
\text { atividades }\end{array}$ & Todas & $\begin{array}{l}\text { Programas e } \\
\text { projetos públicos }\end{array}$ \\
\hline $\begin{array}{l}\text { Destinatários } \\
\text { das informações }\end{array}$ & $\begin{array}{l}\text { Gerente público, } \\
\text { Executivo e } \\
\text { Congresso }\end{array}$ & $\begin{array}{l}\text { Executivo, } \\
\text { Congresso e } \\
\text { Ministério Público }\end{array}$ & $\begin{array}{l}\text { Congresso, } \\
\text { Executivo e } \\
\text { gerente público }\end{array}$ \\
\hline $\begin{array}{l}\text { Valores } \\
\text { administrativos }\end{array}$ & $\begin{array}{l}\text { Eficiência, } \\
\text { efetividade, } \\
\text { economicidade, } \\
\text { qualidade e } \\
\text { desempenho }\end{array}$ & $\begin{array}{l}\text { Conformidade da } \\
\text { gestão, devido } \\
\text { processo, } \\
\text { economicidade e } \\
\text { honestidade }\end{array}$ & $\begin{array}{l}\text { Efetividade, } \\
\text { eqüidade e } \\
\text { distribuição de } \\
\text { justiça social }\end{array}$ \\
\hline Tipo de questões & $\begin{array}{l}\text { Avaliativas, } \\
\text { descritivas, de } \\
\text { conformidade e } \\
\text { explanatórias }\end{array}$ & $\begin{array}{l}\text { De conformidade, } \\
\text { descritivas }\end{array}$ & $\begin{array}{l}\text { Avaliativas e } \\
\text { explanatórias }\end{array}$ \\
\hline
\end{tabular}


(continuação)

\begin{tabular}{|c|c|c|c|}
\hline $\begin{array}{l}\text { Natureza da } \\
\text { determinação / } \\
\text { recomendação }\end{array}$ & $\begin{array}{l}\text { A ação governa- } \\
\text { mental pode } \\
\text { funcionar } \\
\text { melhor se... }\end{array}$ & $\begin{array}{l}\text { A ação governa- } \\
\text { mental deve ser } \\
\text { mais correta se... }\end{array}$ & $\begin{array}{l}\text { O bem-estar } \\
\text { social pode } \\
\text { ser melhorado } \\
\text { se a ação } \\
\text { governamental... }\end{array}$ \\
\hline $\begin{array}{l}\text { Concepção da } \\
\text { administração } \\
\text { pública }\end{array}$ & $\begin{array}{l}\text { Provedora de } \\
\text { serviços e normas } \\
\text { que visem regular } \\
\text { a sociedade de } \\
\text { forma eficiente e } \\
\text { efetiva }\end{array}$ & $\begin{array}{l}\text { Esfera burocrá- } \\
\text { tica do Estado } \\
\text { que visa imple- } \\
\text { mentar políticas } \\
\text { públicas de forma } \\
\text { correta e honesta }\end{array}$ & $\begin{array}{l}\text { Provedor de } \\
\text { serviços que } \\
\text { visem o bem- } \\
\text { estar coletivo }\end{array}$ \\
\hline $\begin{array}{l}\text { Ameaças } \\
\text { para EFS }\end{array}$ & $\begin{array}{l}\text { Questionamento } \\
\text { quanto à legiti- } \\
\text { midade do órgão } \\
\text { para exercer } \\
\text { determinados } \\
\text { trabalhos }\end{array}$ & $\begin{array}{l}\text { Insulamento do } \\
\text { órgão, imagem de } \\
\text { ineficaz, de ine- } \\
\text { ficiente e de impe- } \\
\text { dir a moderniza- } \\
\text { ção do serviço } \\
\text { público }\end{array}$ & $\begin{array}{l}\text { Tornar-se vulne- } \\
\text { rável à medida } \\
\text { que as conclu- } \\
\text { sões de seus } \\
\text { trabalhos trata- } \\
\text { rem de mérito de } \\
\text { política pública. } \\
\text { Trabalhos podem } \\
\text { ser muito longos } \\
\text { e de alto custo }\end{array}$ \\
\hline $\begin{array}{l}\text { Oportunidades } \\
\text { para EFS }\end{array}$ & $\begin{array}{l}\text { Complementar } \\
\text { seus trabalhos } \\
\text { de controle da } \\
\text { conformidade da } \\
\text { gestão com traba- } \\
\text { lhos de controle } \\
\text { de resultados da } \\
\text { gestão. Melhoria } \\
\text { da imagem e forta- } \\
\text { lecimento demo- } \\
\text { crático }\end{array}$ & $\begin{array}{l}\text { Mostrar-se como } \\
\text { guardião do Erário } \\
\text { contra improprie- } \\
\text { dades adminis- } \\
\text { trativas, inclusive } \\
\text { corrupção }\end{array}$ & $\begin{array}{l}\text { Órgão gerador } \\
\text { de informações } \\
\text { sobre efetividade } \\
\text { de políticas pú- } \\
\text { blicas, que pode } \\
\text { ser de grande } \\
\text { interesse para } \\
\text { o seu principal } \\
\text { cliente - o Con- } \\
\text { gresso. Contribuir } \\
\text { para melhoria do } \\
\text { bem-estar coletivo }\end{array}$ \\
\hline $\begin{array}{l}\text { Requisitos } \\
\text { internos da EFS } \\
\text { para conduzir } \\
\text { trabalhos }\end{array}$ & $\begin{array}{l}\text { Independência, } \\
\text { profissionalismo e } \\
\text { conhecimento } \\
\text { técnico abran- } \\
\text { gente do funcio- } \\
\text { namento estatal }\end{array}$ & $\begin{array}{l}\text { Independência, } \\
\text { profissionalismo } \\
\text { e conhecimento } \\
\text { técnico de } \\
\text { procedimentos } \\
\text { administrativos }\end{array}$ & $\begin{array}{l}\text { Independência, } \\
\text { profissionalismo } \\
\text { e conhecimento } \\
\text { técnico de funcio- } \\
\text { namento de pro- } \\
\text { gramas e projetos } \\
\text { públicos }\end{array}$ \\
\hline $\begin{array}{l}\text { Relação } \\
\text { com o auditado }\end{array}$ & $\begin{array}{l}\text { Trabalhos mais } \\
\text { próximos. Média/ } \\
\text { baixa distância } \\
\text { relacional }\end{array}$ & $\begin{array}{l}\text { Trabalhos estan- } \\
\text { ques. Alta distân- } \\
\text { cia relacional }\end{array}$ & $\begin{array}{l}\text { Trabalhos } \\
\text { em conjunto. } \\
\text { Baixa distância } \\
\text { relacional }\end{array}$ \\
\hline $\begin{array}{l}\text { Modalidade } \\
\text { da aplicação }\end{array}$ & Avaliação/revisão & Atestação & $\begin{array}{l}\text { Avaliação/ } \\
\text { pesquisa }\end{array}$ \\
\hline
\end{tabular}




\begin{tabular}{|l|l|l|l|}
\hline $\begin{array}{l}\text { Habilidades } \\
\text { do auditor }\end{array}$ & $\begin{array}{l}\text { Nível de espe- } \\
\text { cialização abran- } \\
\text { gente (economia, } \\
\text { gerenciamento } \\
\text { público, ciência } \\
\text { política, direito, } \\
\text { administração } \\
\text { pública, análise } \\
\text { de políticas } \\
\text { públicas) }\end{array}$ & $\begin{array}{l}\text { Nível de } \\
\text { especialização } \\
\text { finanças públicas } \\
\text { pública) }\end{array}$ & $\begin{array}{l}\text { Nível de } \\
\text { especialização } \\
\text { específico } \\
\text { (análise de } \\
\text { políticas públicas } \\
\text { e economia) }\end{array}$ \\
\hline $\begin{array}{l}\text { Concepção } \\
\text { de controle } \\
\text { externo }\end{array}$ & $\begin{array}{l}\text { Provedor de } \\
\text { informações } \\
\text { sobre resultados } \\
\text { da ação pública, } \\
\text { identificando } \\
\text { pontos de pos- } \\
\text { sível melhoria. } \\
\text { Guardião dos } \\
\text { resultados da } \\
\text { ação pública }\end{array}$ & $\begin{array}{l}\text { Provedor de } \\
\text { informações } \\
\text { funcionamento bom }\end{array}$ & $\begin{array}{l}\text { Provedor de } \\
\text { informações } \\
\text { sobre o impacto } \\
\text { das ações } \\
\text { governamentais. }\end{array}$ \\
\hline $\begin{array}{l}\text { Guardião do bem- } \\
\text { estar social } \\
\text { decorrente da } \\
\text { ação pública }\end{array}$ \\
\hline
\end{tabular}

\section{Auditoria de desempenho e gerenciamento público}

Para fins de discussão do tema auditoria de desempenho, accountability de conformidade pode ser relacionada com modelos que refletem idéias da Administração Pública Progressista (Hood e Jackson, 1991). Tais modelos referem-se, entre outros, a formas tradicionais de auditoria de conformidade baseadas em demonstrativos financeiros, processos de certificação, busca da legalidade e cumprimento do devido processo legal. Essas práticas espelham um conjunto de idéias sobre a maneira que se julga apropriada para se desenvolver os processos de responsabilização e transparência da gestão no âmbito do serviço público. Essas idéias se baseiam em justificativas e valores denominados por Hood e Jackson (1991:11) como do tipo theta. ${ }^{15}$ Accountability de desempenho refere-se a idéias pertencentes ao recente campo do conhecimento sobre o fenômeno da administração governamental denominado Nova Gestão Pública (NPG), ${ }^{16}$ tais como: tipos de auditoria de desempenho, baseadas em critérios de eficiência, economia, efetividade, boas práticas de gestão, boa governança, qualidade de serviço e atendimento de metas (Pollitt et al., 1999: 90), cujas justificativas estão próximas dos valores do tipo sigma.

As duas espécies fundamentais de revisão ex-post da atividade governamental acima relatadas podem ainda ser distinguidas pelos modelos mentais com os quais se idealiza o funcionamento governamental (Barzelay, 
1997:387). A auditoria de conformidade estaria, nesse caso, relacionada com o modelo mental de funcionamento do governo como uma máquina burocrática orientada por regras e normas rígidas (Mintzberg, 1983: 163). A auditoria de desempenho estaria mais relacionada com um tipo particular de burocracia denominado burocracia profissional (ibid., 189), baseada em mais imparcialidade, capacidade técnica e profissionalização.

A Administração Pública Progressista (APP) e a NGP ${ }^{17}$ podem ser definidas como filosofias administrativas (Hood e Jackson, 1991; Hood, 1994). ${ }^{18}$ Filosofias administrativas podem ser caracterizadas como um conjunto de doutrinas coerentes e justificadas que se tornam aceitas em determinado período histórico como resposta a questões de como organizar o setor público. Cameralismo, APP e NGP são exemplos de filosofias administrativas. ${ }^{19}$

De acordo com a definição acima, o estudo da auditoria de desempenho pode ser relacionado com as doutrinas pertencentes ao conjunto de idéias da NGP. Uma forma de se abordar o estudo das idéias em NGP é analisar o "fator de aceitação". ${ }^{20}$ Alguns governos vêm aceitando as idéias da NGP como alternativas viáveis na agenda de discussão para os processos de tomada de decisão governamental (Kingdon, 1984) ${ }^{21}$ relacionados com reformas administrativas desde o fim da década de $1970 .{ }^{22}$

As idéias contidas na NGP podem ser também identificadas como respostas à crescente preocupação sobre a maneira pela qual a burocracia havia "capturado" o sistema político e, dessa forma, passou a ditar as regras de formulação e implementação de políticas públicas (Aucoin, 1990: 116; Self, 1993: 157). Da mesma maneira, ressaltou-se a necessidade do restabelecimento da primazia de princípios gerenciais sobre a máquina burocrática (Metcalfe e Richards, 1987: 35). Nessa veia histórica, a NGP é mais bem caracterizada como a conjunção de idéias de duas escolas de pensamento: a Escola de Escolhas Públicas e a Escola Gerencialista, ${ }^{23}$ que dominaram os processos de reforma administrativa em vários países pelo mundo, notadamente aqueles pertencentes ao chamado Westminster System (Aucoin, 1990: 119). Em resumo, a NGP pode ser definida como uma filosofia administrativa adotada no âmbito de diversas administrações públicas nacionais a partir do final da década de 1970, que contém um conjunto de doutrinas coerentes e justificadas. ${ }^{24}$ Essas doutrinas endereçam a questão de como a administração pública deve se organizar para prover bens e serviços públicos. Tais questões se colocam em um lugar entre o processo de formulação e implementação de políticas públicas de um lado, e o de doutrinas de gerenciamento público e teorias correlatas, de outro.

Finalmente, o termo NGP pode ser analisado como um campo de argumentação e pesquisa, conduzidos internacionalmente, sobre o processo de intervenção de políticas de gerenciamento público no âmbito governamental. A NGP, de acordo com Barzelay, é um campo de discussão 
política e profissional, conduzido internacionalmente, sobre política de gerenciamento público, liderança executiva, design de organizações programáticas e operações governamentais.

Assim definidos, argumentação e pesquisa sobre gerenciamento público devem focar os processos políticos e organizacionais pelos quais mudanças de políticas públicas ocorrem. ${ }^{25}$ Além disso, trabalhos endereçando essa disciplina deveriam focar em análise substantiva de políticas de gerenciamento público (Barzelay, 2001: capítulo 6). A abordagem para a NGP, caracterizada neste parágrafo, parece ser a mais adequada para a discussão do tema auditoria de desempenho.

\section{O argumento político e organizacional da auditoria de desempenho}

Diferentemente de auditoria de regularidade, o desenvolvimento da auditoria de desempenho implica questionamentos sobre a distribuição de autoridade e controle no processo de formulação de políticas públicas. Ao mediar as tensões entre os órgãos legislativos e executivos, as EFS representam instituições de significância constitucional singular e distinta (White et al., 1994). A capacidade de conduzir auditoria de desempenho que possa afetar o processo de formulação de política pública, entretanto, não depende somente do grau de independência, especialização e profissionalismo dessas instituições. Tais condições são necessárias, mas não são suficientes. O desenvolvimento de auditoria de desempenho depende mais do ambiente político e organizacional que uma EFS estiver posicionada.

O que deve ser salientado nesse ponto é que a maneira que uma EFS conduz a auditoria de desempenho é conformada e limitada por fatores intra-estatais, mais que uma questão técnica que demonstre o melhor caminho de controlar e revisar procedimentos de um governo. ${ }^{26}$ De fato, não há um conjunto programático coerente de maneiras com as quais EFS conduzem a auditoria de desempenho. Pelo contrário, essas entidades têm desenvolvido diferentes tipos de controle por resultados e melhores práticas sobre o mesmo rótulo de auditoria de desempenho.

Evidências empíricas entre os países da OCDE demonstram que poucas são as EFS que realmente enfatizam questões de conteúdo ou mérito de política pública ao desenvolver trabalhos de auditoria de desempenho. Este é o caso somente na Austrália, Holanda, Suécia e Estados Unidos (Barzelay, 1997: 396). ${ }^{27}$

\section{$O$ argumento gerencial da auditoria de desempenho}

No presente ensaio, o argumento gerencial para análise da auditoria de desempenho estará relacionado com dimensões de reformas 
administrativas e o seu impacto nos trabalhos das EFS. Dentre essas dimensões, destacam-se:

- privatização;

- marketização;

- descentralização;

- governo por resultados;

- construção de indicadores de desempenho;

- sistemas de qualidade total;

- controle social;

- transparência governamental;

- reforma regulatória;

- responsabilização por resultados;

- gerencialismo; e

- teorias de escolhas públicas (public choice).

Trabalhos recentes sobre gerenciamento público discorrem sobre as maneiras pelas quais reformas administrativas ocuparam espaço na agenda política de diversos países. Não é objeto do presente estudo, todavia, tratar desses processos, mas sim os seus impactos nos trabalhos das EFS.

Os mecanismos de alteração nas estratégias de atuação e nos modelos de controle utilizados pelas EFS decorrentes de reformas administrativas podem ser assim sintetizados:

- alterando o mandato, os poderes das EFS. Impondo o uso de técnicas e novas formas de controle;

- alterando os objetos de controle e sua estrutura (por exemplo, a privatização);

- criando novas formas de gerenciamento do setor público (por exemplo, orçamento por resultado e governo por programas);

- gerando novos dados relevantes para o sistema de controle (por exemplo, indicadores de desempenho);

- utilizando internamente técnicas e abordagens gerenciais (por exemplo, gerenciamento por resultados no âmbito das EFS);

- criando critérios específicos de eficiência, efetividade e economia com reflexos internos nas EFS; e

- utilizando novas técnicas e metodologias nos trabalhos de EFS (por exemplo, utilização de técnicas regulatórias nos trabalhos de auditoria, benchmarking, competição).

Constata-se, por fim, que existe também um processo de indução efetuado pelas EFS nos processos de reformas administrativas, de duas maneiras:

- as recomendações/determinações das EFS em seus relatórios podem também afetar os processos da reforma; e

- os regulamentos e normas expedidas pelas EFS podem alterar os processos da reforma. 
O processo de auditoria

de desempenho

A auditoria de desempenho pode também ser caracterizada como uma cadeia de insumo-produto. Nesse caso, podemos então definir seus insumos, processos, produtos e impactos?

É possível analisar o livro de Pollitt et al. (1999) sobre essa ótica, pois sua divisão esquemática permite que se identifiquem alguns destes fatores, como por exemplo:

- insumos: competências das EFS, habilidades profissionais etc.;

- processo: trabalhos de campo, aplicação de técnicas e métodos etc;

- produto: relatório de auditoria, recomendações determinações; e

- impactos: melhorias, aumento da transparência, accountability democrática etc.

Figura 1: Esquema do processo de auditoria de desempenho

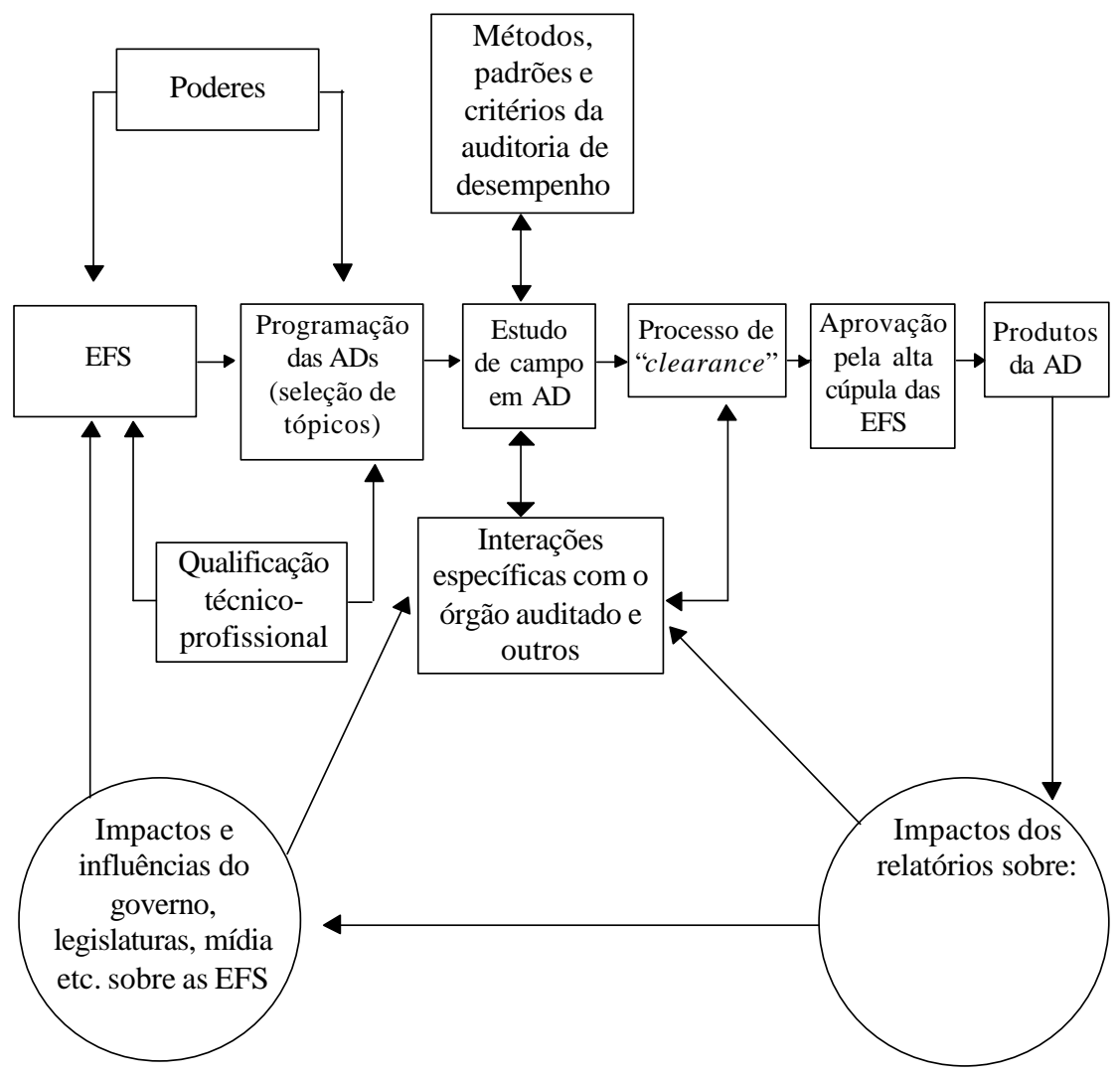



de desempenho

Os auditores de desempenho, diferentemente dos auditores tradicionais, não usam um invariável conjunto de regras e padrões, eles são "obrigados" a desenhar cada novo trabalho de auditoria de desempenho, como se fosse um produto único e não um conjunto de verificações uniformes como em uma linha de montagem.

Eles devem definir os objetos de estudo, estabelecer os critérios apropriados, escolher as ferramentas adequadas para investigação, exercer várias outras habilidades, que podem incluir a diplomacia e capacidade de trabalho em equipe. Os trabalhos de auditoria de desempenho geralmente recebem uma forte atenção da imprensa e dos órgãos oficiais. Além disso, os papéis do auditor governamental (veja a Figura 2) tendem a ampliar à medida que alguma das EFS resolva expandir sua capacidade para desenvolver auditorias de desempenho. A figura a seguir busca demonstrar os diversos papéis que os auditores de desempenho podem assumir ao desenvolver trabalhos utilizando-se dos diversos critérios em auditoria.

\section{Figura 2: Possíveis papéis para}

\section{auditores de desempenho}

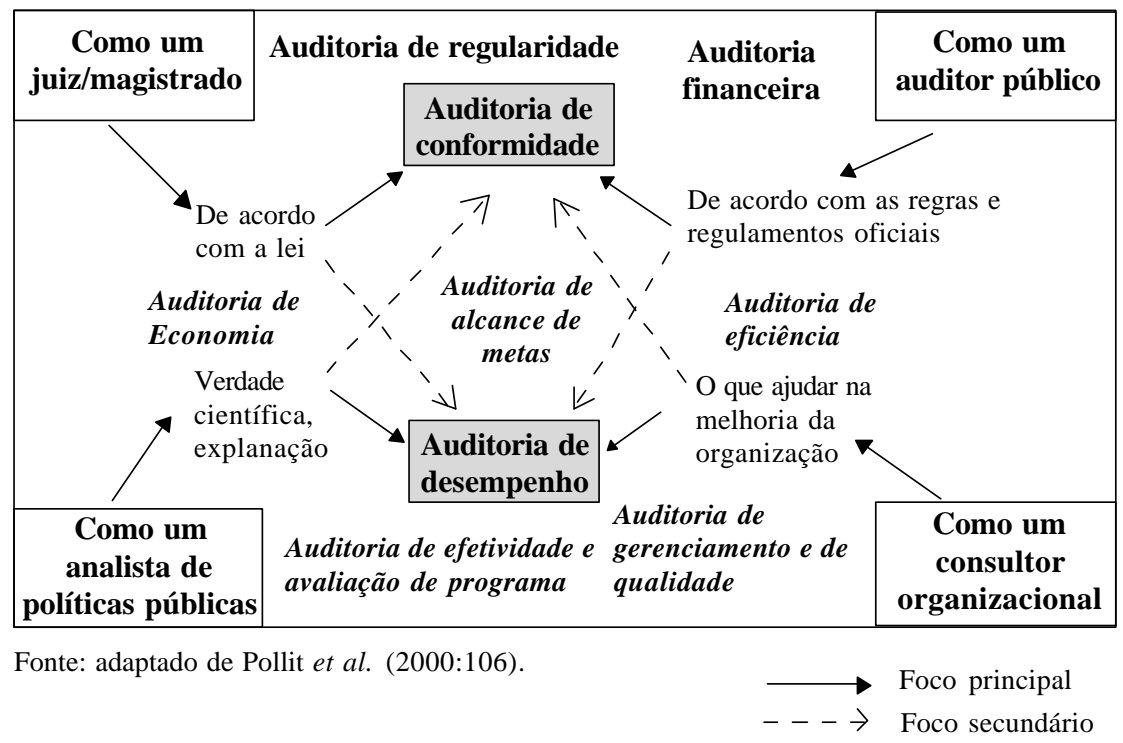


De acordo com Pollitt et al. (1999), os métodos utilizados pelas EFS por eles pesquisados em trabalhos de auditoria de desempenho são mais variados que os da auditoria tradicional.

As principais constatações relativas aos métodos utilizados podem ser assim resumidas:

- aumento no número de métodos;

- apesar dos avanços, as EFS continuam a basear suas conclusões em evidências decorrentes de exame documental e entrevistas;

- uso crescente de consultas com usuários e fornecedores de serviços públicos (questionários);

- uso de material secundário;

- métodos mais voltados para as ciências sociais;

- uso limitado de comparações internacionais; e

- a transparência de abordagens utilizadas pelas EFS ainda está bastante distante daquelas utilizadas por avaliadores acadêmicos, sendo que as escalas de entrevistas são raramente publicadas, o número e tipo de entrevistas, as condições da observação e outros métodos de rigor mais científicos.

\section{Produtos}

O trabalho de Pollitt et al. classifica os seguintes tipos de produtos da auditoria de desempenho:

- o próprio relatório;

- sumários;

- extratos;

- livros;

- artigos;

- brochuras informativas;

- memorando;

- notas técnicas;

- ensaios de seminários; e

- relatórios periódicos sobre a atividade.

Segundo os autores, características de um bom relatório de auditoria de desempenho devem incluir:

- os relatórios devem ser equânimes e justos, neutros e objetivos;

- ter bastante credibilidade;

- serem úteis; e

- interativos e abertos. 
Auditoria decorrente do problema do agente-principal (Flint, 1988)

Uma interpretação válida sobre a decisão estratégica de diversas EFS em controlar as ações governamentais por resultados pode advir do seguinte fato - agentes formuladores de políticas públicas estão possivelmente enfrentando um problema do agente-principal. A necessidade dos "principais" (formuladores de políticas públicas) em monitorar os trabalhos de seus "agentes" (implementadores de políticas públicas) promove a ascensão da atividade de auditoria na esfera governamental (Power, 1997:16). Os contratos de gestão na esfera pública, os objetivos das políticas, os mandatos dos órgãos públicos ou os acordos de desempenho (performance agreements) entre ministros/políticos (principais) e seus subordinados (agentes) devem ser auditados e revisados. Devido ao distanciamento (inclusive de informações) entre os principais e seus agentes e à complexidade das matérias que devem ser revisadas, os principais encontram-se inabilitados de realizar esse monitoramento e, assim, requisitam os serviços de um auditor (Flint, 1988).

A teoria do agente-principal é um constructo pertencente ao campo de estudo da escola de economia novo institucionalista. Tal teoria baseiase nas seguintes premissas para alcançar sua conclusão:

- os agentes fazem escolhas para os principais (estrutura da decisão);

- os principais não podem rever todas as escolhas adotadas (estrutura da informação), $\operatorname{logo} . . ;$ e

- os principais deveriam fornecer "incentivos" para forçar os agentes a adotarem "boas escolhas".

Esta teoria está baseada na seguinte racionalidade:

- o processo pelo qual agentes realizam suas escolhas é uma função de custo e oportunidade; e

- tal função pode ser maximizada se os agentes tiverem incentivos para fazerem boas escolhas para os principais. ${ }^{28}$

Situar a atividade de auditoria, inclusive de desempenho, como decorrente do problema do agente-principal pode ser uma ferramenta teórica importante para explicar o comportamento das diversas EFS que resolveram recentemente incorporar entre os seus portfólios de produtos de revisão e avaliação governamental as diversas modalidades ou tipos de auditoria de desempenho que foram aqui tratadas.

Tendo como base essa teoria, pode-se afirmar que as tendências observadas em diversas administrações públicas em valorizar os resultados da ação estatal como ferramenta de incremento da estabilidade democrática e de justificativa - perante um público "desacreditado" sobre o papel do Estado - que este pode fornecer produtos de qualidade e de valor, a atividade de auditoria torna-se essencial, pois vai descrever e corroborar esse alcance da ação estatal. 


\section{Melhorando significativamente o desempenho das ações governamentais - o modelo de Peter Aucoin (1995)}

$\mathrm{O}$ argumento central de Peter Aucoin (1995), autor do livro New Public Management - Canada in a comparative perspective, é o de que a melhoria do desempenho do governo é alcançada se os objetivos de políticas são estabelecidos e comunicados de forma clara. Além disso, e não menos importante, o gerenciamento público será menos sujeito a sucumbir as "patologias" burocráticas se os objetivos contidos nas políticas públicas possuírem sentido operacional concreto por intermédio de planos, metas e indicadores de desempenho. Por fim, quando os objetivos das políticas são claros, existe maior probabilidade de que ocorra o aprendizado organizacional por intermédio de avaliações de políticas e programas.

Em nível estratégico de formulação de políticas públicas e decisões quanto a despesas estatais, além da necessidade de disciplina política (partidária), o aumento do desempenho só pode ser alcançado por intermédio de medidas dos resultados da ação governamental, tais como indicadores de desempenho, planos de ação, metas de desempenho e padrões de qualidade de serviço. Acima de tudo, deve-se, obrigatoriamente, buscar maior clareza dos objetivos pretendidos pelos ministros (políticos) quando formulam iniciativas de políticas públicas.

Segundo Aucoin, a experiência coletiva dos quatro sistemas por ele analisados, na tentativa de melhorar a clareza dos objetivos das políticas públicas visando à melhoria do desempenho do serviço público, aponta para uma direção comum. Em cada caso, maior transparência tem sido implementada em duas frentes: o que os ministros pretendem alcançar e o que os gerentes do serviço público devem fornecer; além disso, como a efetividade, eficiência e economia devem ser analisadas e avaliadas.

Contudo, as formas de se alcançar tais objetivos seguiram diferentes estratégias. No Canadá e na Austrália, o foco tem sido na implementação de "planos" ministeriais e departamentais. Na Grã-Bretanha e na Nova Zelândia, "contratos" entre ministros e as organizações do serviço público são usados como estratégias de alcance desses objetivos.

O mérito de uma abordagem por "planos", segundo seus defensores, é que eles garantem que os objetivos do governo permanecem no centro de comando governamental (formulação) e não são sucumbidos pelas atividades utilizadas para o seu alcance (implementação). O "o que fazer" não se confunde com o "como fazer", garantindo aos políticos o chamado 
pulso público. Para garantir a melhoria do desempenho, contudo, essa abordagem demanda que haja prioridade sobre a efetividade dos planos em realizar os resultados pretendidos. As conexões entre os objetivos da política e o design dos programas requerem rigoroso uso de avaliação de efetividade de programas. A Austrália, inclusive, utiliza um sistema de avaliação nos processos de formulação de políticas (análise de política pública ex-ante). O Canadá tem adotado um sistema formal de avaliação de programas.

Por outro lado, o mérito da abordagem contratual é que existe uma separação de responsabilidades por resultados e produtos. ${ }^{29}$ Os gerentes responsáveis pela condução de políticas pública seriam os responsáveis perante os ministros/políticos pelos produtos das políticas públicas; por sua vez, os ministros/políticos (executivos) seriam os responsáveis perante o sistema de controle (parlamento) pelos resultados da atuação estatal. Aucoin faz uma avaliação bastante positiva dessa abordagem e cita o caso da Nova Zelândia como o mais notável exemplo de melhoria de desempenho e aumento da accountability devido a esses contratos de desempenho (performance agreements) de produtos e resultados (outputs e outcomes). ${ }^{30}$

\section{Críticas ao modelo de Peter Aucoin (1995)}

As críticas ao modelo de Aucoin serão propostas à medida que descrevermos os modelos de Hood (1998) e de Wilson (1989). Verificarse-á que a contratualização do serviço público pode ser efetiva apenas em alguns ambientes culturais de administração pública. Além disso, pesquisas empíricas sobre o funcionamento de agências públicas demonstram que o conhecimento sobre operações governamentais indica que a atividade governamental não é um fenômeno monolítico. De fato, a efetividade de contratos e "planos" como forma de solucionar o problema de governança estatal (principal argumento de Aucoin) podem encontrar espaço pleno em apenas alguns tipos de culturas administrativas e em singular modalidade de agência pública, entre outras três em que teriam de ser analisados os tipos de contratos e planos que poderiam ter sucesso de implementação.

Em suma, a abordagem contratual pode encontrar três problemas básicos, que as teorias cultural (Hood) e contigencial (Wilson) podem nos auxiliar a compreender:

- recompensar ou punir servidores públicos por desempenho;

- identificar, quantificar e qualificar o valor público; e

- mensuração de desempenho e observabilidade de produtos/resultados da ação pública. 


\section{O modelo gerencial de reformas administrativas - auditoria de desempenho e o modelo de Allen Schick sobre a NGP na Nova Zelândia}

Allen Schick (1996) fornece uma análise crítica sobre a excessiva ênfase contratual do modelo de reforma da Nova Zelândia. Os sistemas de controle de mensuração de desempenho de produtos e resultados (outputs e outcomes) deveriam ser utilizados como ferramentas gerenciais para melhoria do processo decisório em formulação e implementação de políticas públicas, mais do que como ferramentas de accountability pura.

Nessa perspectiva, o principal elemento de controle seria reforçar a cultura gerencial (empowered management culture — Roth, 1996: 253). De fato, questões gerenciais vêm sendo priorizadas nos trabalhos das EFS ao conduzirem auditorias de desempenho. No Dutch Algemene Rekenkamer (EFS holandesa), auditoria de desempenho utilizando como critério boas práticas de gestão somam 76, entre 1993-1995, contra 29, baseadas em economia, quatro em eficiência e em efetividade (Pollitt et al., 1999:96). O NAO (EFS britânica) conduz seus trabalhos de VFM, utilizando critérios de boas práticas gerenciais em vários de seus estudos. Esse tipo de critério aumentou de 28, entre 1983-1985, para 43, no período entre 1993-1995. Esse é o mais usado dos critérios dos estudos de VFM do NAO (Pollitt et al., 1999:98). Apesar de a Intosai afirmar que a avaliação dos 3 E's é o maior motivo pelo qual as EFS conduzem a auditoria de desempenho; na prática, pelo menos dois desses três E's (eficiência e efetividade) têm sido muito menos objeto de investigação que questões de práticas e procedimentos de boa gestão.

O modelo gerencial de reforma administrava distingue-se do modelo contratual porque baseia-se em "planos", não em contratos. Uma vez que planos são acordados entre os principais e os agentes, seu atendimento não está vinculado a recompensas ou sanções, mas em uma responsabilidade subjetiva (Gregory, 1995) de servidores públicos de buscarem atender ao que foi planejado por meio de um ethos voltado ao interesse público e à satisfação em atendê-lo. A principal idéia gerencial que norteia essa visão baseia-se em assegurar boas práticas gerenciais por intermédio de sistemas de gerenciamento e controladoria (management and accounting control systems). Dessa forma, definir a visão e missão, alinhar as variáveis críticas de desempenho com a estratégia organizacional, mensurá-las adequadamente e criar padrões ou metas para se alcançar essa estratégia passam a ser dimensões essenciais, na visão gerencial, para se obter o sucesso de atuação das organizações públicas. Sucesso gerencial, de acordo com doutrinas de gerenciamento e controladoria aplicadas ao setor público (Kaplan e Norton, 1996; Boyle, 1989), pode ser assim sintetizado: 
1) estratégia e visão devem ser claramente traduzidas em objetivos e metas e comunicadas aos diversos níveis gerenciais;

2) objetivos e metas devem ser expressos por medidas específicas, estar relacionados com o planejamento de longo prazo, e as iniciativas devem estar alinhadas com a alocação de recursos orçamentários e financeiros;

3) visão e objetivos devem estar ajustados com o tipo de organização pública, em termos de critérios particulares de eficiência e efetividade;

4) indicadores de desempenho devem ser monitorados e avaliados periodicamente; e

5) informações gerenciais devem ser usadas de forma a alavancar o sistema de feedback e aprendizagem.

Literatura e pesquisas sobre gerenciamento público indicariam alguns problemas em se alcançar, na esfera pública, esses requerimentos de boas práticas gerenciais advindas de doutrinas de gerenciamento e controladoria (Wilson, 1989; Hood, 1998; Moore, 1995; Bardach; 1998). Com efeito, se a missão e os objetivos são mandatos, de acordo com Bardach, esses mandatos são quase sempre obsoletos na esfera pública. Além disso, de acordo com a avaliação de Moore, tais mandatos são quase sempre "vagos". Se metas podem ser comparadas com produtos e resultados (outputs/outcomes), de acordo com o quadro teórico de Wilson, eles são observáveis ao mesmo tempo em apenas um caso de agência pública — agências de produção. Se a visão gerencialista visa criar uma responsabilidade subjetiva dos agentes públicos para o atendimento da missão do órgão, sem contudo recompensar/punir esses agentes por bom/ mau desempenho, tal estratégia seria efetiva apenas em contextos culturais de administração hierárquicos ou igualitários, mas não em contextos individualistas ou fatalistas (Hood, 1998).

Uma abordagem gerencial é menos rígida sobre a mensuração do desempenho que a abordagem contratual. De fato, sistemas de informações de desempenho são utilizados para dar direção e apoiar o processo decisório, não para punir ou recompensar. Trata-se de ferramenta gerencial mais de planejamento que de controle (no sentido estrito de comptrol Dunsire, 1978). Por outro lado, o modelo contratual parece ser superior no que diz respeito a criar uma accountability clara entre formuladores de políticas e controle externo (legislatura) e entre principais e agentes.

Especificidades do setor público demonstram que os modelos gerenciais (planos) e contratuais encontram sérias limitações para ser implantados de forma pura na esfera governamental. Existem contingências (Wilson, 1989), bem como sistemas de valores, crenças e conhecimentos (Dent, 1991) no setor público que impedem o desenvolvimento de sistemas gerenciais e contratuais nas suas formas puras. Portanto, afirma-se que outros constructos deveriam ser considerados de forma a observar essas 
especificidades, para que possa ser obtido sucesso na implementação de uma ação governamental orientada ao desempenho. Dessa forma, alcançando maior accountability governamental, bem como criando um ambiente auditável de desempenho.

\section{Auditoria de desempenho e teoria cultural aplicada ao gerenciamento público e ao controle (Hood, 1998; 2000)}

De acordo com Hood, a teoria cultural pode explicar o comportamento do gerenciamento público. Existem quatro "maneiras de vida": fatalista, hierarquista, individualista e igualitária, todas derivadas das dimensões de grupo e grid que podem ser relacionadas com formas de controle e regulação na esfera pública (Hood, 1998:51). Por exemplo, uma forma de controle - externo (oversight) é derivada de uma concepção de "chefismo" relacionada com uma maneira hierarquista de ver o mundo. Hood exemplifica essa doutrina com a cadeia militar de comando e os censores imperiais chineses. Outras três formas de controle referem-se a controle aleatório calculado ("chancismo"), competição (escolha) e mutualidade ("grupismo"). Todos esses tipos genéricos são estendidos em outras quatro formas que representam variantes do mesmo viés cultural.

O Quadro 2 mostra as quatro dimensões culturais resultantes da definição de grupo e grid aplicados para a administração pública. Em cada uma das quatro dimensões, buscou-se identificar como se comportam cinco aspectos que consideramos importantes em nosso estudo:

1) controle: indica a principal forma de controle, segundo essa cultura administrativa;

2) contrato: demonstra como deve comportar a implantação da visão contratualista nesse contexto cultural;

3) gerenciamento: demonstra como deve comportar a implantação da visão gerencialista neste contexto cultural;

4) ethos: indica os principais valores, crenças e conhecimentos dos componentes desta cultura administrativa; e

5) doutrina: indica, em uma única palavra, qual o modelo mental que afeta o comportamento dos indivíduos deste contexto cultural. 
Quadro 2: Teoria cultural e auditoria de desempenho

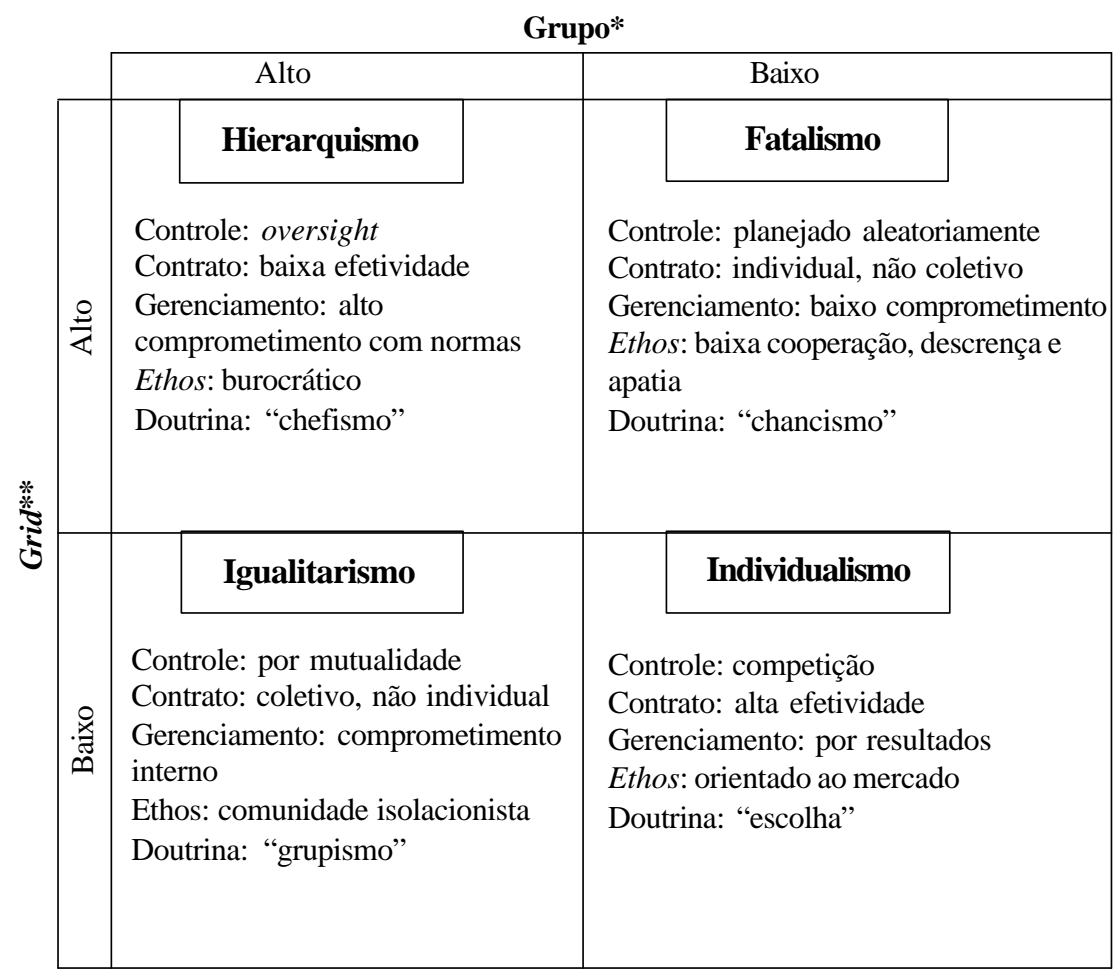

* Medida que o gerenciamento público envolve coletividades coerentes, diferenciadas institucionalmente de outras esferas da sociedade.

** Medida que o gerenciamento público é conduzido de acordo com regras gerais bem compreendidas e estabelecidas.

Fonte: adaptado de Hood (1998: 9, 53, 235).

\section{Hierarquismo, fatalismo, igualitarismo ou individualismo?}

A teoria cultural aplicada ao gerenciamento público oferece um cenário bastante propício para se desenvolver argumentos sobre auditoria de desempenho na esfera governamental, notadamente no que se refere aos principais tipos de reformas administrativas que apregoam que "contratos" de desempenho podem ser uma solução viável para resolver problemas decorrentes da tensão entre políticos e burocratas (em outros termos, entre a formulação e a implementação de políticas públicas).

Problemas de mensuração e viabilidade de observação de desempenho, contudo, permanecem não resolvidos pela teoria cultural. O primeiro problema refere-se à dificuldade de se estabelecer um valor pecuniário para os produtos e resultados do serviço público. De fato, a administração pública visa precipuamente criar valor público, diferentemente da administração privada que visa criar valor de mercado (dinheiro). Outro problema 
refere-se à mensuração e à observação de produtos e resultados da ação

governamental. O modelo que descreveremos a seguir demonstra tal dificuldade. Finalmente, cabe destacar que a dificuldade de mensuração está relacionada tanto com a viabilidade quanto com o custo de se coletar essas informações (Thompsom, 1991).

\section{O controle por oversight - culturas hierarquistas}

Em culturas hierarquistas de administração, a auditoria de desempenho pode ser inefetiva se ela se basear em uma abordagem eminentemente contratual (veja argumento de Aucoin sobre reformas de Westminster), pois o ethos burocrático de tais organizações pode levar a efeitos reversos. O paradigma dessas organizações é orientado por regras específicas; nesse sentido, alçar os gerentes dessas culturas a uma condição de "livres para gerenciar" torna-se tarefa muito difícil. Os gerentes de tais culturas almejam trabalhar em ambientes estritamente legalistas e estão, de fato, menos comprometidos com o atendimento de resultados que em desempenhar procedimentos já prescritos. Portanto, a estratégia de tais organizações deve estar muito bem desenhada. A missão, a visão e os objetivos devem estar bastante alinhados com as metas. A auditoria de desempenho nessas organizações deveria focar em aspectos gerenciais das organizações, mais que estritamente em resultados. Além do mais, os contratos geralmente especificam os produtos e resultados, mas não definem como atingi-los, pois é tarefa gerencial. Uma organização hierarquista precisa de normas (procedimentos) que demonstrem como desempenhar uma tarefa e como atingir um objetivo. Se o desenho de como atingir essas metas está claro, os resultados devem ser atingidos pelo alto viés de grupo e grid. Nesse contexto, accountability de conformidade/legalidade e auditoria de boas práticas de gestão parecem ser mais efetivas que uma abordagem de auditoria de desempenho do tipo 3 E's.

\section{O controle por mutualidade - culturas igualitárias}

Em culturas igualitárias, os contratos entre principais e agentes devem ser acordados com a coletividade, não individualmente. A baixa propensão para competitividade (Dunleavy e Hood, 1994) em tal contexto cultural faz que formas de controle diferentes de controle interno por pessoas do mesmo grupo seja inefetivo. Além disso, tais organizações são resistentes a controles externos, à medida que elas tendem a se isolar de outras esferas da sociedade. O Village World dos mandarins do Governo Executivo Britânico (Heclo e Wildavsky, 1974), bem como o Tesouro 
Neozelandês (Schick, 1996) são exemplos de tais culturas organizacionais. A auditoria de desempenho em tais contextos pode ser inefetiva para afetar comportamentos e padrões. Esse contexto cultural exige do auditor de desempenho um maior trabalho de "diplomacia" com vistas a quebrar as resistências do auditado ao trabalho de um outsider.

\section{O controle randômico - culturas fatalistas}

Uma organização de cultura fatalista deve estabelecer contratos individuais de desempenho e checá-los randomicamente, pois as pessoas dessas organizações tendem a responder a normas externas, especialmente se houver recompensas ou sanções por bom (mau) desempenho. Entretanto, tais comunidades têm um baixo comprometimento ao gerenciamento e a aspirações coletivas. Eles desejam estar de acordo com normas externas para evitar punições, entretanto, estão menos propensos ao comprometerem-se com a estratégia organizacional. A auditoria de desempenho neste contexto deve focar, por exemplo, a confiabilidade dos sistemas de controles interno, a capacidade de gerenciamento de desempenho da organização, bem como manter a possibilidade de se checar, randomicamente, contratos individuais de desempenho.

\section{O controle por competição - culturas individualistas}

Uma organização de cultura individualista poderia ser caracterizada como aquela de melhor cenário para uma relação contratual ser efetiva nos termos sustentados pela teoria do agente-principal. De acordo com a perspectiva individualista, a efetiva accountability no serviço público significa fazer produtores responsáveis pelos consumidores em uma relação de mercado, da mesma forma que as empresas privadas afirmam ser responsáveis por seus clientes (Hood, 1998:55). Contrato seria o "instrumento" que deveria estabelecer uma relação clara entre fornecedorconsumidor em termo denominado por Allen Schick (1996) como acordos de desempenho.

\section{Teoria contigencial de Wilson (1989) e as formas de controle de agências públicas}

De acordo com o modelo de Aucoin, produtos e resultados são estabelecidos como sempre observáveis e mensuráveis na esfera governamental. A teoria contingencial de Wilson (1989) demonstra, entretanto, 
que a burocracia não é um fenômeno monolítico. Produtos e resultados não são sempre observáveis na esfera pública (veja quadro abaixo). $\mathrm{Na}$ verdade, apenas em um singular tipo de agência pública (de produção), produtos e resultados são ambos observáveis. ${ }^{31}$

\section{Quadro 3: A matriz de Wilson}

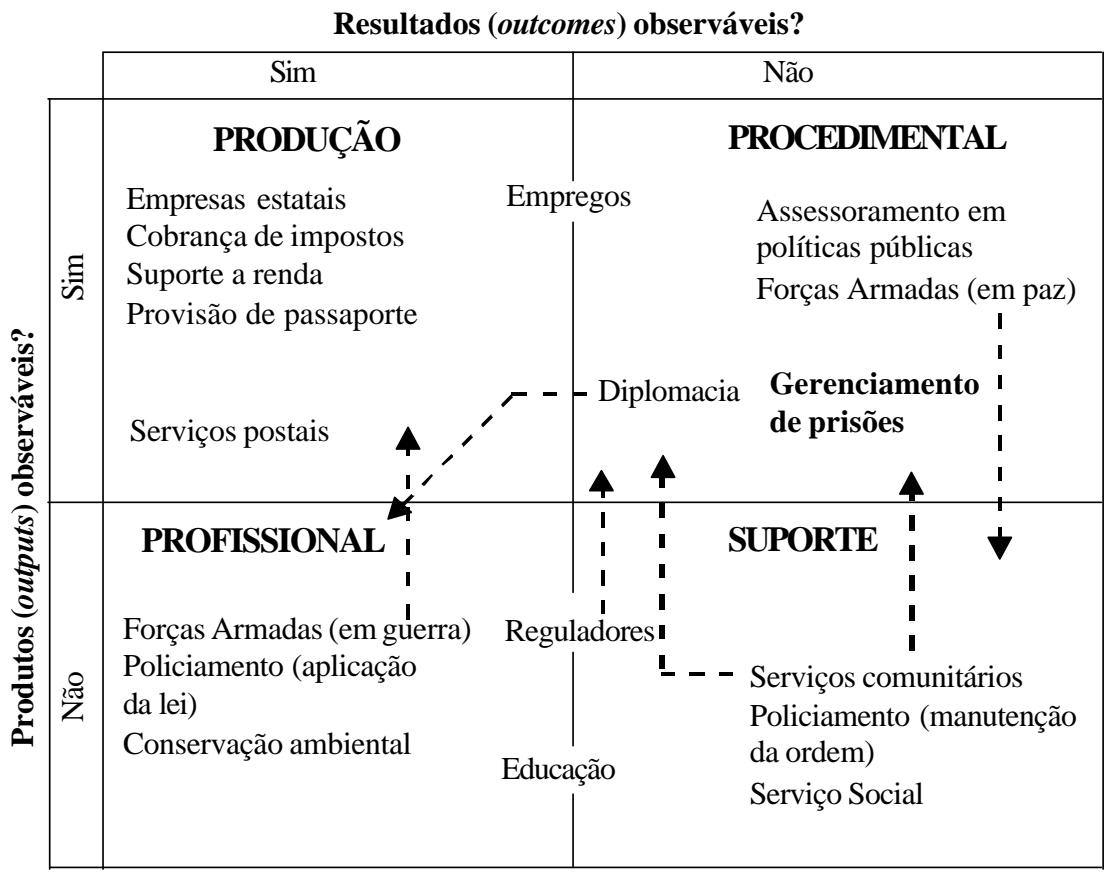

Fonte: adaptado de Gregory (1995: 58-59).

O trabalho de Gregory (1995) tomou como base a matriz de Wilson para endereçar críticas severas sobre o modelo contratual das reformas administrativas da Nova Zelândia. Baseada fortemente em conformidade com produtos, argumenta o autor, as reformas da Nova Zelândia levaram a perda de foco dos objetivos das políticas públicas, pois a exagerada preocupação com a accountability gerencial ocorreu em detrimento da responsabilidade administrativa (agir no interesse público), especialmente em contextos de agências diferentes daquelas de produção (produtos e resultados observáveis).

Como resposta a essa deficiência, prossegue em seu argumento, um forte senso de missão, comprometimento com normas e valores profissionais, confiança mútua, lealdade e respeito devem nortear as ações das agências, principalmente as profissionais e de suporte (Gregory, 1995:62). A responsabilidade subjetiva definida por Gregory pode ser interpretada como um ethos de interesse público, um valor central da filosofia da administração pública progressista, o que demonstra que as reformas não devem subestimar 
os valores já existentes na cultura burocrática, sob pena de levarem a uma situação menos favorável a criação de valor público que a anterior.

Evidências empíricas têm sugerido que uma orientação para o desempenho exclusivamente baseada em um modelo contratual não é propriamente adequada na esfera pública. Problemas como service creaming (Corevellec,1997), conformidade excessiva com objetivos estreitos (Schick, 1996:24-26; Hood, 1998:218) e custos de implementação de sistemas de gerenciamento de desempenho (Thompson, 1993:305), em detrimento de resultados de longo prazo (impacto) de políticas públicas, parecem não ser raros em contextos de reformas baseadas estritamente em contratos.

A presente análise do modelo contratual de reformas administrativas com enfoque no desempenho das ações governamentais pode estar refletindo no modo como as EFS têm conduzido trabalhos de auditoria de desempenho. De fato, pesquisas empíricas sobre os tipos de auditoria de desempenho conduzidas pelas EFS têm identificado que apenas a Filândia, a Nova Zelândia e a Suécia conduzem trabalhos de auditoria de informações de desempenho (Barzelay, 1997:395).

\section{Auditoria de desempenho e tipos de agências governamentais}

\section{Agências de produção}

Nessa espécie de agências, todos os tipos de auditoria de desempenho são cabíveis e desejáveis, pois é possível observar os produtos e resultados de sua atuação. Com efeito, o custo de implementar um sistema de gerenciamento de desempenho não deve ser tão oneroso, devido à facilidade de se obter informações de desempenho. Dessa forma, uma abordagem contratual é bastante apropriada para o aumento da accountability e do desempenho desse tipo de agência. Contudo, se o viés cultural de uma agência não for individualista, problemas de conformidade com o contrato podem surgir. Em suma, agências de produção que trabalham em um ambiente cultural individualista parece ser o mais efetivo contexto para uma abordagem contratual. Em outras circunstâncias, modelos híbridos (entre contrato e gestão) podem ser mais apropriados.

\section{Agências procedimentais}

Nesse tipo de agência, devido à impossibilidade de se observar os impactos de sua atuação, auditorias de desempenho baseadas em critérios de efetividade não parecem ser adequadas. Uma abordagem contratual em termos de produtos poderia ser efetiva, mas não baseada em impactos, respeitando o contexto cultural. ${ }^{32}$ 


\section{Agências profissionais}

Agências profissionais deveriam ser objeto de avaliação de programas e de auditoria de efetividade de desempenho, pois seus impactos podem ser observados. Uma abordagem contratual deveria visar medidas de impacto, mas não de mensuração de produtos. Um exemplo refere-se quando os detetives de departamentos policiais são avaliados em termos de crimes resolvidos (Wilson, 1989:166). Um contra-exemplo seria quando o número de processos abertos, mesmo sem solução, indica medidas de desempenho; nesse cenário, os agentes poderiam abrir muitos casos investigativos, mesmo sem suficientes provas, para aumentar "aparentemente" seu desempenho (Corevellec, 1997).

\section{Agências de suporte}

Em agências de suporte, os produtos e os impactos são muito difíceis de serem observados. Em agências genuinamente de suporte, qualquer uso de accountability contratual irá criar um ambiente "inauditável". Pois esse ambiente carece de produtos e impactos mensuráveis e observáveis, essenciais para que o processo de auditoria aconteça (Power, 1996). Um modelo gerencial parece ser, nesta situação, o único modelo viável para melhoria do desempenho e assegurar um certo grau de accountability de desempenho. Neste contexto, a auditoria de desempenho deve enfocar os aspectos gerenciais de tais agências.

\section{Construção de uma base de conhecimento em auditoria de desempenho}

Segundo Power (1996 e 1997), falta uma base de conhecimento e um ambiente negociado entre auditores e auditados sobre os critérios recentes utilizados para auditorias de desempenho (não-financeira) no âmbito tanto do setor público como privado.

O livro de Michael Power, The Audit society: Rituals of Verification, destaca a "explosão" das formas da função auditoria como mecanismo de controle sobre as ações governamentais e sociais. Não se pretende esgotar o argumento do livro, que, na verdade, perpassa não só a questão da ascensão das auditorias de desempenho sobre outras formas de controle governamental, mas demonstra como outras entidades não genuinamente de auditoria (como classe médica e acadêmica) buscam nos rituais de verificação de qualidade, eficiência, economicidade e efetividade, mimetizar os trabalhos de auditores e, na prática, encontram 
as mesmas dificuldades de implementação de sistemas robustos de controle, quando se usa critérios de resultado para se determinar os "achados" de auditoria.

$\mathrm{O}$ argumento conduzido aqui é simples, na verdade mais breve do que simples, pois, trata-se do argumento central do livro de Power, que pode ser assim sintetizado:

- a atividade de auditoria necessita de uma base de conhecimento sobre a qual os rituais de verificação possam ser desenvolvidos; e

- deve existir uma negociação entre entidades auditoras e agentes auditados sobre o que deverão constituir os processos de auditoria.

De acordo com essas premissas, conclui o autor que: falta uma base de conhecimento e um ambiente negociado entre auditores e auditados sobre os critérios recentes utilizados para auditorias de resultado (nãofinanceira) no âmbito tanto do setor público como privado.

De acordo com o autor, os programas de alavancagem de governança e controle, afetando a atividade de auditoria, vêm se expandido na esfera pública por três motivos:

1) NGP: caracterizada por mudanças observáveis de estilo de administrações públicas;

2) regulação caracterizada como iniciativas de controle de recursos de entidades reguladas para garantir conformidade de suas ações; e

3) aumento de iniciativas de gerenciamento da qualidade, bem como o desenvolvimento de novos mercados e oportunidades profissionais de serviços de certificação. No livro, Power trata da auditoria médica, auditoria acadêmica e auditoria ambiental.

Segundo o autor, estes três desenvolvimentos programáticos a ascensão de uma nova gestão pública, um salto no estilo de regulação governamental e a ascensão de certificações de qualidade — constituem a demanda principal por um particular estilo de controle nos mais variados campos.

Todo esse processo de transformação, denominado de reinvenção de governança, conduz também a alterações nos processos de auditoria. Dessa forma, a tecnologia da atividade de auditoria deve ser constantemente adaptada para "fazer os objetos de auditoria auditáveis". Tais transformações devem ocorrer de duas formas:

- adaptando o ambiente de auditoria com vistas a atingir os objetivos por meio de criação de medidas de desempenho auditáveis; e

- construindo a credibilidade institucional do próprio conhecimento operacional dos órgãos auditores (base de conhecimento).

Em suma, as auditorias funcionam porque as organizações auditadas literalmente se fizeram auditáveis; a atividade de auditoria demanda um ambiente auditável, em forma de sistemas, medidas de desempenho, que constrói um certo estilo de verificação possível. 


\section{Considerações finais}

As EFS têm-se destacado, em vários países, como órgãos fundamentais para a consolidação de Estados democráticos e para o aumento da transparência, accountability e melhoria da gestão pública. Tal destaque parece decorrer da imagem de independência, competência técnica e profissionalismo que essas instituições buscam adquirir ao incorporar critérios, métodos e técnicas de auditoria de desempenho.

No presente ensaio, auditoria de desempenho foi analisada como uma disciplina pertencente ao campo de estudos de políticas de gerenciamento público. Tais políticas são consideradas como os principais focos de estudos da Nova Administração Pública (Barzelay, 2001). Tal definição permite uma abordagem da auditoria de desempenho como um campo de pesquisa e argumentação acadêmica, bem como de discussão entre profissionais do governo sobre políticas de intervenções gerenciais em governos executivos. Assim definido, a argumentação sobre auditoria de desempenho fornecida neste ensaio teve como foco os processos políticos e organizacionais que as mudanças na formulação e condução de políticas públicas ocorrem. Além disso, buscou-se salientar que uma análise do aspecto gerencial da auditoria de desempenho também é recomendável.

Conforme argumenta Nelson (1996), devido ao fato de o gerenciamento público, como o campo de estudo das políticas públicas, ser uma área de métodos e objetos difusos, torna-se bastante improvável criar-semecanismos de acumulação sistemática de conhecimento e de criação de uma teoria geral. Mas de forma alguma se deve abandonar a idéia de "conhecer e transformar o mundo" ao mesmo tempo. Talvez esse seja o maior desafio dos auditores de desempenho da gestão governamental, pois além do conhecimento de seus objetos de estudo, os auditores devem propor mudanças significativas em práticas de gestão do órgão, projeto, programa ou atividade governamental auditados, com vistas ao aumento da accountability democrática, bem como da melhoria do serviço público.

Os conhecimentos de conteúdos metodológicos das ciências sociais, de economia e de análise de gerenciamento do setor público, por exemplo, adquiridos pelo auditor de desempenho, são certamente mais abrangentes que aqueles do auditor tradicional (de conformidade/legalidade). O objetivo central de se tentar construir um arcabouço metodológico para a disciplina auditoria de desempenho é o de criar uma argumentação rigorosa e uma análise de perspectiva comparativa sobre o papel das EFS em uma nova administração pública que visa, além da adequação e da conformidade dos atos de gestão, resultados melhores.

Argumentou-se neste ensaio que a auditoria de desempenho pertence ao campo de estudos do gerenciamento público. Alguns trabalhos recentes nessa área (Hood et al., 1999; Pollitt et al., 1999; Barzelay, 1997) 
demonstram que essa atividade é uma "indústria" crescente na esfera a auditoria de desempenho nesta dimensão não é apenas uma tarefa possível, mas também recomendável.

\section{Notas}

1 O conceito de gerenciamento público é equiparado, no presente contexto, com o conceito de política pública tal como definido por William Dunn como parcialmente uma disciplina descritiva que "busca o conhecimento sobre causas e consequiências de políticas públicas", bem como uma disciplina normativa, cujo propósito adicional é "a criação e crítica de afirmações, conhecimentos e juízos de valor sobre políticas públicas". Ao equiparar essas duas abordagens, a palavra gerenciamento deve ser posicionada entre as palavras política e pública. O termo política de gerenciamento público corresponde ao convencional, mas ambíguo, termo reforma administrativa. As políticas de gerenciamento público são meios administrativos de que dispõem gerentes públicos para guiar, motivar e controlar o serviço público de forma global (Barzelay, 2001).

2 Os instrumentos de políticas de gerenciamento público são normas institucionais e rotinas organizacionais em áreas de planejamento de despesas públicas e gerenciamento financeiro, políticas concernentes a servidores públicos e relações trabalhistas, compras no setor público, organização e métodos, auditoria e avaliação (Barzelay, 2001:23).

3 EFS é o termo pelo qual os órgãos públicos responsáveis pelo controle externo de burocracias do setor público são reconhecidos internacionalmente. O Tribunal de Contas da União (TCU), Brasil; o National Audit Office (NAO), britânico; a Cour des Comptes, Francesa; e o General Accounting Office (GAO), norte-americano, são exemplos dessa espécie de instituição.

4 A presente doutrina parece refletir uma aproximação razoável das práticas observadas nas EFS pesquisadas no presente estudo. De fato, nem todas EFS conduzem práticas de auditoria de performance sistematicamente, mas a maioria delas e de forma crescente. Contrariamente, todas as EFS pesquisadas conduzem alguma modalidade de auditoria de conformidade.

5 Performance auditing é o nome reconhecido internacionalmente como a modalidade de auditoria que visa avaliar os aspectos de economicidade, eficiência e efetividade de programas, políticas, organizações e atividades públicas. Evidências empíricas demonstram que a auditoria de desempenho inclui outras modalidades de revisão além da eficiência, efetividade e economicidade ( $3 \mathrm{E}$ 's), tais como: atendimento de metas, boas práticas de gestão, boa governança, capacidade de gerenciamento de desempenho, análise de risco, qualidade de serviço, entre outros. Para fins de discussão deste ensaio, performance auditing será denominada auditoria de desempenho.

6 Accountability - obrigação de responder por uma responsabilidade outorgada. Pressupõe a existência de, pelo menos, duas partes: uma que delega a responsabilidade e outra que a aceita, com o compromisso de prestar contas da forma como usou essa responsabilidade (Escritório do Auditor-Geral do Canadá, 1995).

7 Essa constatação também é válida no que diz respeito aos modelos de controle da legalidade e conformidade de um governo (Power, 1997; Chelinsk, 1985). 
8 A lei de criação do novo modelo do NAO é relativamente recente, de 1983. A partir dessa data, aquele órgão começou a implementar as auditorias de Value for Money (VFM), que podem ser classificadas como auditorias de desempenho. O novo regulamento do NAO preconiza expressamente que os trabalhos conduzidos pelo órgão não podem abordar questões de mérito de políticas públicas. Em entrevista com servidores daquela entidade que desenvolvem trabalhos de VFM (VFM studies) afirmou-se que essa restrição é muitas vezes difícil de ser compreendida, pois ao se conduzir estudos dessa espécie, selecionar tópicos que tratam de mérito da política e implementação da política, muitas vezes é tarefa subjetiva - "It is a grey area" — afirmou o auditor do NAO.

9 Essa dicotomia foi inicialmente tratada por Max Weber que, apesar de não abordar essa questão nesses termos, descreveu o processo de formação da burocracia e o distanciamento do processo burocrático do processo político. Woodrow Wilson (1887), em trabalho entitulado Public Administration, criou as bases da formação da administração pública norte-americana, que deveria ser composta por um corpo técnico distinto para implementar as políticas públicas definidas pelo Congresso. Portanto, aos políticos caberia a formulação das políticas públicas e à burocracia, sem interferência direta do primeiro, a sua implementação. Ressalte-se que reformas administrativas recentes visam muitas vezes devolver aos políticos o controle da burocracia que de certa forma "capturou" os agentes públicos formuladores de políticas públicas (agentes políticos). Os agentes públicos não-eleitos avançaram sua esfera inicial de atribuições e, por uma série de fatores passaram, na prática, a formular e implementar as políticas públicas.

${ }^{10}$ Exemplos de EFS que conduzem esse tipo de trabalho são a Alemanha, Estados Unidos e Suécia.

${ }^{11}$ Em estudo de título "Paradigmas de Controle", o Tribunal de Contas da União denominou de instrumentos de controle as espécies de procedimentos para obtenção de informações relevantes para o controle externo. A atividade de auditoria figura como um dos instrumentos listados. Outros se referem à denúncia, prestação de contas, solicitação de informações etc.

${ }^{12}$ Essa definição de auditoria de desempenho contrasta com a definição de auditoria de regularidade por que essa última enfatiza procedimentos de atestação como a principal atividade do auditor, enquanto auditoria de desempenho engloba estudos mais aprofundados sobre o funcionamento do setor público como um todo. Auditoria de regularidade estaria relacionada com accountability financeira, auditoria de controles internos, auditoria de probidade e propriedade de decisões administrativas e modalidades semelhantes.

${ }^{13}$ Pollitt et al. (1999) definem como critérios de auditoria de desempenho os de eficiência, economia e efetividade. Os métodos englobam desde questionários até modelagem de dados.

${ }^{14}$ Análise de políticas públicas é uma ferramenta conhecida de planejamento no domínio público (Friedman, 1987:151). O modelo econômico de análise de política pública fornecido por Friedman coloca essa disciplina como fornecedora de informações e consultoria para formuladores de políticas públicas (Ibid: 139).

15 Valores do tipo sigma, theta e lambda são conjuntos de valores administrativos em gerenciamento público que justificam um argumento administrativo. O primeiro enfoca a eficiência (custos) e a efetividade (outputs/outcomes) com o principal valor do gerenciamento público. O segundo - tipo theta - enfoca que o gerenciamento público deve ser organizado de forma a privilegiar e controlar aspectos de honestidade e a justiça; e o último, valores do tipo lambda, ressaltam a flexibilidade e a robustez administrativa como principais valores que devem nortear o gerenciamento público (Hood e Jackson, 1991: 12 e Hood; 1991:11). 
${ }^{16}$ Hood et al. (1999: 6) afirmam que muito da retórica da NGP ressalta a relativa importância da auditoria de desempenho, contrastando essa com auditoria de conformidade. Tal retórica enfatiza uma "mudança de uma prescrição tática para uma prescrição estratégica, de comando direto para indireto, de instruções detalhistas para mais liberdade com certos limites, notadamente os relacionados a resultados". A NGP, de acordo com Barzelay, é um campo de discussão política e profissional - conduzida internacionalmente sobre política de gerenciamento público, liderança executiva, design de organizações programáticas e operações governamentais.

${ }^{17}$ Uma versão norte-americana do termo NGP é denominada Reinventado o Governo (1992), encontrada no livro de mesmo nome de Osborne and Gaebler (1992). O livro de Barzelay Breaking Through Bureaucracy (1992) atribui o termo paradigma pós-burocrático para contrastá-lo com o paradigma anterior, o burocrático.

${ }^{18}$ Hood cunhou o termo New Public Management (NGP), em seu artigo seminal A Public Management for All Seasons? (1991), para designar as reformas administrativas levadas a efeito no âmbito da administração pública de diversos países, especialmente àqueles do sistema de Westminster (Canadá, Inglaterra, Nova Zelândia, Austrália). O termo Progressive Public Administration (APP) foi introduzido pelo artigo de Hood (1994), Key for Locks in Public Administration, bem como pelo seu livro Explaining Policy Reversal (capítulo 7) para designar e contrastar o "clima progressista" de idéias no âmbito da administração pública que imperava antes da ascensão das idéias contidas na NGP no começo dos anos 80 e 90.

${ }^{19}$ Discussão aprofundada sobre o "pacote" doutrinário contido em filosofias administrativas é encontrada em Hood e Jackson (1991), capítulo 8 e Hood (1994), capítulo 7.

${ }^{20}$ Hood and Jackson 1991 enxergam o campo de conhecimento do gerenciamento público como uma ciência dialética na qual propostas de adoção de certos tipos de doutrinas, entre as diversas possibilidades de argumentos administrativos, são aceitos se o argumento que suporta essa proposta possui um poder retórico forte o bastante para convencer a audiência relevante. Dessa forma, a ascensão e o domínio no clima de opinião sobre determinada filosofia administrativa é mais bem explicada se o poder retórico e de persuasão de determinado argumento administrativo é analisado. Em resumo, o fator de aceitação.

${ }^{21}$ De acordo com esse autor, a formação da agenda de discussão de um governo determina que matérias ou problemas serão abordados pelos formuladores de decisões; a especificação das alternativas viáveis determina quais soluções eles devem considerar quando uma decisão deve ser levada a efeito.

${ }^{22}$ A NGP foi deflagrada durante a gestão da primeira-ministra britânica Margareth Thatcher em 1979.

${ }^{23}$ Aucoin (1990) destaca o livro de Peter and Walterman, In Search of Excellence (1982), como o melhor exemplo e claramente a mais influente literatura sobre a introdução de práticas e idéias gerenciais na esfera do setor público. Do ponto de vista de políticas públicas, ele identifica o trabalho de Niskanen, Representative Government and Bureaucracy (1971), como o que melhor representa o espírito do conjunto de idéias da Escola de Escolhas Públicas.

${ }^{24}$ Aucoin (1990) identifica paradoxos entre a Escola de Escolha Pública e a Gerencialista. Tais paradoxos, contudo, parecem ser menos importantes à medida que os fenômenos da NGP são analisados empiricamente.

${ }^{25}$ O que parece estar implícito nessa discussão é assumir que a administração pública está incrustada na cultura social de que ela deriva. Portanto, a cultura política e a cultura administrativa devem ser objeto de estudo caso se deseje entender o fenômeno administrativo no setor público. Para uma discussão sobre a relação entre cultura política, cultura administrativa e administração pública, veja Peters (1995), capítulo dois. 
${ }^{26} \mathrm{Um}$ arcabouço teórico sobre os fatores intra-estatais e externos que podem influenciar a estratégia das EFS com vistas a adotar determinados tipos de auditoria de desempenho pode ser encontrado em Gomes (2001). Esse texto busca discutir a dimensão política da auditoria de desempenho, tomando como caso duas EFS: o General Accounting Office $(G A O)$, EFS americana e o $N A O$; EFS britânica, identificando fatores explanatórios para a adoção de critérios de efetividade e avaliação de programas pelo $G A O$, e as dificuldades na condução de critérios que utilizam efetividade e questionamento de mérito ou conteúdo de políticas públicas pela EFS britânica.

${ }^{27}$ Os estudos de $V F M$ conduzidos pelo $N A O$ não incluem avaliação de programas ou julgamentos sobre conteúdo de políticas públicas.

${ }^{28}$ Uma análise sobre tentativas de uso da teoria do agente-principal para explicar comportamentos no "mundo real" pode ser encontrada em Arrow (1985). O autor conclui que o poder explanatório dessa teoria para explicar comportamentos de agentes econômicos é relativamente fraco. Conforme veremos adiante nesse estudo, existem diversos problemas em se utilizar essa teoria para explicar o comportamento de agentes públicos.

${ }^{29}$ As críticas a esse modelo de contrato podem ser encontradas em Barzelay (2001), capítulo 4.

${ }^{30}$ No texto do professor Allen Schick, de título New Zealand in Time of Changes: the spirit of the reforms (1996), algumas críticas são oferecidas aos modelos de reforma implementados por aquele país. Entre elas, a contratualização exacerbada sem um enfoque gerencial pode levar a diversos desvios na condução e elaboração das políticas públicas. Entre elas a definição de objetivos pouco ousados e metas de fácil atendimento, com vistas a alcançar as recompensas por seu atendimento - políticos (votos) e servidores públicos (prestígio e recompensas pecuniárias).

${ }^{31}$ Evidências empíricas em países da OCDE indicam algumas dificuldades em se determinar claramente os produtos e resultados no setor público. Em publicação de 1994, aquele organismo internacional declarou que: "respostas a essas novas visões de gerenciamento público requerem que os países avancem na melhoria do desempenho, de forma que os benefícios alcançados sejam demonstrados, na medida do possível. Ao mesmo tempo, contudo, as complexidades e limitações inerentes à própria mensuração do desempenho na esfera governamental devem ser reconhecidas, para que as informações de desempenho sejam usadas de forma apropriada e positivamente (OECD Performance Management in Government, oㅡ 3, p. 92, 1994).

32 Vale notar que o contexto cultural pode ser afetado por contingências externas. Um exemplo refere-se ao aumento, ainda que pequeno, do número de indicações para ocupação do topo do serviço público britânico por outsiders (notadamente gerentes da iniciativa privada). 


\section{Referências bibliográficas}

Allison, G. (1984), "Are Public and Private Management Fundamentally Alike in All Unimportant Respects?", in Stillman, R. (ed.), Public Administration: Concepts and Cases. Boston: Houghton Mifflin, p. 283-298

Arrow, Kenneth J. (1985), “The Economics of Agency”, in Pratt, John W. (ed.), Principals and Agents: The Structure of Business. Boston: Harvard Business School, p.37-51.

AucoIn, Peter. (1990), "Administrative Reform in Public Management: Paradigms, Principles, Paradoxes and Pendulums". Governance, 3,2, p.115-37.

(1995), The New Public Management: Canada in Comparative Perspective. Montreal: IRPP.

BARZELAY, Michael. (1992), Breaking through Bureaucracy: A New Vision for Managing in Government. Berkeley: University of California Press.

. (1997), "Central Audit Institutions and Performance Auditing: A comparative Analysis of Organisational Strategies in the OECD". In Governance, vol. 10 , no 3, p. 235-260.

. (2001), The New Public Management: Improving Research and Policy Dialogue. Berkeley: University of California Press.

BARDACH, Eugene. (1998), Getting Agencies to Work Together: The Practice and Theory of Managerial Craftsmanship. Washington, DC: Brookings.

Boyle, Richard. (1989), Managing Public Sector Performance: A Comparative Study of Performance Monitoring Systems in the Public and Private Sectors. Institute of Public Administration.

Centro Latino Americano de Administração para o Desenvolvimento (ClAD). (2000), Uma Nova Administração Pública para América Latina.

CoReveliec, H. (1997), Stories of Performance: Narrative Features of organisational Performance. New Brunswick, NJ: Transaction Books.

Dent, Jeremy. (1991), "Accounting and Organizational Cultures: A Field Study of the Emergence of a New Organizational Reality". In Accounting, Organizations and Society, vol. 16, no 8, p. 705-732.

Dunleavy, Patrick; Hood, Christopher. (1994), "From old Public Administration to New Public Management”. In Public Money and Management, july-september, 1994.

Dunn, William. (1994), Public Policy Analysis. Englewood Cliffs, NJ: Prentice-Hall.

DunsiRE, Andrew. (1978), The Execution Process. Oxford: Martin Robertson.

ELSTER, Jon. (1989), Nuts and Bolts for the Social Sciences. Cambridge: Cambridge University Press.

FLINT, D. (1988), Philosophy and Principles of Auditing. London: Macmillan.

FrIEDMan, John. (1987), Planning in the Public Domain: from Knowledge to Action. Princeton, NJ: Princeton University Press.

GARCiA, Ronaldo Coutinho. (2001), "Subsídios para Organizar Avaliações da Ação Governamental". Textos para Discussão, IPEA.

Gomes, Marcelo Barros. (2001), "Performance Audit Argument: a Public Management Policy Analysis about Supreme Audit Institutions Role". Revista Del CLAD, no 7 XV Concurso de Ensayos y Monografías sobre Reforma del Estado y Modernización de la Administración Pública. "Control y Evaluación del Desempeño Gubernamental". Ensayos Gandores, 2001.

Gregory, RJ. (1995), “Accountability, Responsibility, and Corruption: Managing the Public Production Process", in Boston, J. (ed.), The State Under Contract. Wellington, Bridget Williams. 
Gray et al. (1993), Budgeting, Auditing and Evaluation. Functions and Integration in Seven Governments. London: Transaction Publishers.

Glynn, J., Gray, A., Jenkins, B. (1992), "Auditing the Three Es: The Challenge of Effectiveness". In Public Policy and Administration", vol. 7, no 3, Winter.

HatHerLy, D. (1995), The Audit Research Agenda: the Drive for Quality and its Dependence on Professional Judgement. University of Edinburgh.

Heclo, H., Wildavsky, A. (1974), The Private Government of Public Money. London: Macmillan.

Hood, Christopher. (1994), Explaining Economic Policy Reversals. Buckingham: Open University. (1998), The Art of the State. Oxford: Clarendon Press.

Hood, Christopher; et al. (1999), Regulation Inside Government. Waste-Watchers, Quality Police, and Sleaze-Busters. New York: Oxford University Press.

Hood, Christopher; JACKsON, Michael. (1991), Administrative Argument. Aldershot, Dartmouth. . (1994). "Key for Locks in Administrative Argument". Administration and Society, 25,4, p. 467-488.

Intosal. (1992), Auditing Standards. International Organisation of Supreme Audit Institutions.

Kaplan, R., Norton, D. (1996), The Balanced Scorecard: Translating Strategy into Action. Boston: Harvard Business School Press.

Kingdon, John. (1984), Agendas, Alternatives, and Public Policies. Boston: Little, Brown. Light, Paul. (1993), Monitoring Government. Washington: Brookings Institute.

Majone, G. (1989), Evidence, Argument, and Persuasion in the Policy Process. Yale UP, New Haven.

Metcalfe, L., Richards, S. (1987), Improving Public Management. SAGE Publications Ltd.

MintzBerg, H. (1983), Structure in fives: Designing effective organizations. Englewood Cliffs, NJ: Prentice-Hall.

Moore, M. (1995), Creating Public Value: Strategic Management in Government. Cambridge, MA: Harvard University Press.

Nelson, B. (1996), "Public Policy and Administration: An Overview", in Goodin, R., Klingermann, HD. (ed.), A New Handbook of Political Science. Oxford: Oxford University Press, capítulo 24, p. 551-592.

NisKanEN, William. (1971), Representative Government and Bureaucracy. Chicago: Aldine.

Osborne, David; GAEBler, Ted. (1992), Reinventing Government. Reading, MA: AddisonWesley.

Pollitt, Christopher et al. (1999), Performance or Compliance? Performance Audit and Public management in Five Countries. Oxford: Oxford University Press: AddisonWesley.

Peters, Guy. (1995), The Politics of Bureaucracy. 4a ed. New York: Longman.

Peters, T., Waterman, R. (1982), In Search of Excellence. New York: Harper and Row.

Power, M. (1996), “Making things Auditable”. In Accounting, Organisations, and Society, p. 289-315. University Press.

Self, P. (1993), Government by the Market? The Politics of Public Choice. London: Macmillan.

ScHICK, Allen. (1996), The Spirit of Reform: Managing the New Zealand State Sector in Time of Change. Wellington, State Service Commission.

. (1997), The Changing Role of the Central Budget Office. Paris:

OECD/GD(97)109. 
Tribunalde Contas da União (TCU). (2000), Paradigmas do Controle Externo. Grupo de Pesquisa do TCU sobre Tendências do Controle da Gestão Pública Coordenado pelo Ministro Humberto Guimarães Souto.

Walton, D. (1992), Plausible Reasoning in Everyday Conversation. Albany: State University of New York Press.

WeBER, Max. (1979), Economy and Society .

WILSON, Woodrow. (1887), The study of Public Administration. Political Science Quaterly, june, p. 197-202. 


\section{Resumo \\ Resumen \\ Abstract}

\section{Auditoria de desempenho governamental e o papel de Entidades Fiscalizadoras Superiores (FES)}

Marcelo Barros Gomes

O presente trabalho é uma tentativa de fornecer uma argumentação (Dunn, 1994; Hood e Jackson, 1991; Walton, 1992; Majone, 1989; Barzelay, 2000) sobre recentes políticas de gerenciamento público de auditoria e avaliação conduzidas por Entidades de Fiscalização Superior (EFS). Tais políticas vêm refletindo a doutrina de que organizações públicas de controle externo da burocracia estatal devem balancear e integrar duas espécies de accountability democrática: accountability de conformidade e accountability de desempenho (Light, 1993:14; Barzelay, 1997:384; Pollitt et al., 1999: 15; Hood et al., 1999: 6). Nesse contexto, o trabalho busca fornecer um quadro argumentativo, confiável e claro, sobre os processos de auditoria de desempenho na esfera governamental. Argumenta-se que uma abordagem ao estudo de auditoria de desempenho, na condição de recente fenômeno verificável em várias administrações públicas nacionais, deve contemplar três dimensões — a dimensão política, a organizacional e a gerencial — que dão forma e limitam os trabalhos de auditoria das EFS. As dimensões política e organizacional devem ser analisadas recorrendo-se a ferramentas metodológicas de ciência política e administração pública comparada. A dimensão gerencial da auditoria de desempenho deve ser abordada por meio de argumentos baseados em literatura sobre gerenciamento público, doutrinas de administração e gerência; e conhecimento de modelos empíricos sobre o funcionamento de processos e operações governamentais. Concluir-se-á que o processo de escolha das modalidades de auditoria de desempenho por uma EFS é um fenômeno político verificável em diversos países. Portanto, o estudo da dimensão política da auditoria de desempenho deve ser de perspectiva comparativa. Além disso, o trabalho sustenta que ambas as abordagens de reformas administrativas levadas a efeito em diversas administrações públicas nacionais, contratual e gerencial, para uma accountability orientada por resultado no setor público podem ser inconsistentes se os conhecimentos empíricos dos processos e das instituições governamentais não forem levados em consideração. Finalmente, o trabalho busca apresentar uma discussão crítica de como a literatura, a pesquisa e as discussões técnicas acerca do tema auditoria de desempenho podem ser aperfeiçoadas.

\section{Auditoría de desempeño gobernamental y el papel de las entidades fiscalizadoras superiores \\ Marcelo Barros Gomes}

El presente trabajo es un intento de ofrecer una argumentación (Duun, 1994; Hood y Jackson, 1991; Walton, 1992; Majone, 1989; Barzelay, 2000) sobre recientes políticas de gerenciamiento público de auditoría y evaluación conducidas por Entidades de Fiscalización Superior. Tales políticas vienen reflejando la doctrina de que organizaciones públicas de control externo de la burocracia estatal deben balancear e integrar dos especies de accountability democrática: accountability de conformidad y accountability de desempeño (Light, 1993:14; Barzelay, 1997:384; Pollitt et al., 1999:15; Hood et al., 1999:6). En ese contexto, el trabajo pretende brindar un cuadro de argumentación confiable y claro sobre los procesos de auditoría de desempeño en la esfera gubernamental. Se argumenta que al ser abordado el estudio de auditoría de desempeño, en la condición de reciente fenómeno verificable en varias administraciones públicas nacionales, deben tenerse en cuenta tres dimensiones - la dimensión política, la organizativa y la gerencial - que dan forma y limitan los trabajos de auditoría de las EFS. Las dimensiones política y organizativa deben

\section{RSP}

Revista do

Serviço

Público

Ano 53

Número 2

Abr-Jun 2002

Marcelo Barros

Gomes é

Analista

de Finanças

e Controle

Externo do

Tribunal de

Contas da

União .

Contato: marcelobg@ tcu.gov.br 
ser analizadas recorriéndose a herramientas metodológicas de ciencia política y administración pública comparada. La dimensión gerencial de la auditoría de desempeño debe ser abordada por medio de argumentos basados en literatura sobre gerenciamiento público, doctrinas de administración y gerencia; y conocimiento de modelos empíricos sobre el funcionamiento de procesos y operaciones gubernamentales. Se concluirá que el proceso de selección de las modalidades de auditoría de desempeño por una EFS es un fenómeno político verificable en diversos países. Por lo tanto, el estudio de la dimensión política de la auditoría de desempeño debe ser de perspectiva comparativa. Además de eso, el trabajo sostiene que ambos abordajes de reformas administrativas llevadas a cabo en diversas administraciones públicas nacionales, contractual y gerencial, para una accountability orientada por resultado en el sector público pueden ser inconsistentes si los conocimientos empíricos de los procesos y de las instituciones gubernamentales no fueran tomados en cuenta. Finalmente, el trabajo pretende presentar una discusión crítica de cómo la literatura, la investigación y las discusiones técnicas sobre el tema auditoría de desempeño pueden ser perfeccionadas.

\section{Governmental performance auditing and the role of central audit institutions \\ Marcelo Barros Gomes}

This paper is an attempt to provide an argumentation (Dunn, 1994; Hood and Jackson, 1991; Walton, 1992; Majone, 1989; Barzelay, 2000) about recent public management policies of audit and evaluation conducted by Supreme Audit Institutions. Such policies seem to be reflecting the doctrine that a public organisation of external control of the bureaucracy should balance and integrate the pursuit of two types of accountability, namely, compliance accountability and performance accountability (Light, 1993:14; Barzelay, 1997:384; Pollitt et al., 1999:15; Hood et al., 1999:6). An outcome of this paper is to provide a clear and reliable argumentative framework about performance audit. It is argued that performance audit can be characterised as a strand of public management policy. Public management policy is a strand of the New Public Management (NPM). Therefore, analytical frameworks within NPM might be serviceable tools to approach performance audit, as shall be demonstrated. In this sense, the paper tries to build an analytical framework about how to study performance audit phenomenon. It is argued that an approach to the study of performance audit as a recent phenomenon in many national public administrations should hold three streams, namely, political, organisational, and managerial. The political and organisational streams should be analysed with the use of methodological tools within political science and comparative public administration. The latter stream should be approached by policy arguments backed by public management literature, general management doctrines and empirical knowledge about a government processes and operations. It identifies that a choice of Supreme Audit Institutions to conduct performance audit is a political phenomenon. The kernel issue of this paper is to provide an explanatory argument addressing the question of how proper and consistent arguments in favour of the adoption of a performance-orientated control in the public sector are. It is argued that both contractual and managerial approaches to performanceorientated accountability may suffer as a result, if empirical knowledge of governmental processes and institutions are not taken into consideration. Lastly, this paper presents a critical discussion on how literature, research, and professional discussion about performance audit might be improved. 